\title{
Bank capital requirements and mandatory deferral of compensation
}

\author{
Eberhard Feess $^{1}$ - Ansgar Wohlschlegel ${ }^{2}$ (D)
}

\begin{abstract}
We analyze the interplay of capital requirements and mandatory deferral of compensation in reducing banks' risk taking incentives. Two heterogenous banks fund uncorrelated projects with fully diversifiable risk or correlated projects with systematic risk. One of both banks can identify project types and is superior at managing risks. If projects are in abundant supply, full mandatory deferral of compensation is optimal as it allows a larger banking sector without increasing the default risk. With limited supply of projects, deferred compensation may misallocate risky projects to the bank that is inferior at managing risks, so that early compensation may be optimal.
\end{abstract}

Keywords Bank regulation - Capital requirements · Mandatory deferral of compensation

JEL Classification G21 - G28 - D62 · J33

We would like to thank Uli Hege and Robin Lumsdaine for very valuable comments. We are also grateful for discussions with conference audiences at the annual meeting of the European Economic Association (Malaga, 2012) and the Conference of the Financial Engineering and Banking Society (Surrey, 2014). An earlier version was circulated under the title 'Mandatory Deferral of Banker Compensation and Misallocation of Risky Projects'.

$凶 \quad$ Ansgar Wohlschlegel ansgar.wohlschlegel@port.ac.uk

1 Victoria University of Wellington, Wellington, New Zealand

2 Portsmouth Business School, Portsmouth, UK 


\section{Introduction}

\subsection{Motivation and main results}

In the aftermath of the financial crisis, tighter capital requirements (e.g. Admati and Hellwig 2014) and mandatory deferral of bankers' compensation (e.g. Bebchuk and Fried 2010) are the two most prominent suggestions for mitigating the incentives for excessive risk-taking. The European Parliament has released its Capital Requirements Directive IV in April 2013 which increases capital requirements from 2 to $4.5 \%$ for Common Equity Tier 1 capital. Bankers' bonuses are capped to $100 \%$ of the fixum, but are allowed to rise to $200 \%$ if approved by shareholders. At least $40-60 \%$ of variable payments need to be deferred by no less than three to five years. In a similar vein, the Fed established new calculation methods in 2015 for capital ratios, which result in even stricter requirements for global systematically important banks than those mandated under Basel III. ${ }^{1}$ Moreover, although US banks are obliged to achieve a Common Equity Tier 1 capital ratio of $6 \%$ only in 2019, the six largest banks have already taken steps to comply with this requirement earlier. ${ }^{2}$ Discretionary bonus payments during any quarter are prohibited if the bank's eligible retained income is negative and if its capital conservation buffer in the beginning of the quarter was below $2.5 \%$. ${ }^{3}$ These buffer requirements, however, are mandatory only for those large institutions which are seen as critical to avoid globally relevant systemic risks.

While the literature so far mainly restricts attention to either deferred compensation (Hoffmann et al. 2016) or capital requirements (Harris et al. 2017), we contribute to the ongoing discussion on how the risk appetite of financial institutions can be reduced by analyzing the interplay of both of these prominent regulatory instruments. As we focus on the incentives of shareholders to accommodate risky rather than safe projects, we consider the so-called external agency problem between shareholders and society (see in a similar vein e.g. Bolton et al. 2012; Bebchuk and Spamann 2010; Jarque and Prescott 2010; Besley and Ghatak 2013) rather than the internal principal-agent problem between shareholders and bank managers. We make three points: First, mandatory deferral of compensation and tight capital requirements are in many respects substitutes for reducing the risk appetite of shareholders. Second, deferred compensation may be superior to capital requirements as it allows for a larger banking sector without increasing the risk of default. Third, deferred compensation may backfire by misallocating safe and risky projects in a heterogenous banking sector when there is competition for safe projects.

The main building blocks of our model are as follows: In line with the standard approach on banking regulation (Dewatripont and Tirole 1994), we assume that share-

\footnotetext{
1 See e.g. Getter (2012) and PricewaterhouseCoopers, December 2014, at http://www.pwc.com/us/en/ financial-services/regulatory-services/publications/assets/fs-reg-brief-g-sib-proposal.pdf.

2 For more detailed predictions by the Fedeal Reserve, see e.g. http://www.federalreserve.gov/newsevents/ press/bcreg/bcreg20151210a1.pdf. For a comparison of the new regulations $n$ the EU and the US see Jokivuolle et al. (2015).

3 Comparable rules are contained in the European CRD IV which entails five new capital buffers, and firms that do not meet the requirements are constrained in their discretionary distribution of earnings.
} 
holders can externalize part of the default risk to either depositors who do not fully react by demanding appropriately larger interest rates or, via bail-outs, to society. That this agency cost of debt cannot be completely eliminated by relying exclusively on equity finance is a distinctive feature of banks, whose role as financial intermediaries requires them to raise a large amount of debt in the form of deposits. Furthermore, the regulator cannot (fully) tailor capital requirements to the actual project risk. Without these two assumptions, the shareholders' and the society's objective functions would be aligned, so that the external agency problem would disappear. Next, we define mandatory deferral of compensation as the percentage of overall compensation that can only be paid out in case of solvency, i.e. that is junior to all liabilities in case of liquidation. ${ }^{4}$ This ensures that deferred compensation is contingent on success, and this is one of the main purposes of mandatory deferral of compensation (Bebchuk and Spamann (2010)). Finally, we consider a heterogenous banking sector, in which only good banks have screening capabilities to discriminate between safe and risky projects.

With these assumptions in mind, we can now describe our results in greater detail. We first show that, by changing the seniority of compensation claims, mandatory deferral of compensation reduces the shareholders' incentives for risk-shifting. ${ }^{5}$ By contrast to early compensation, bank managers know that they are (fully) paid only in case of solvency, and thus demand a higher salary in the non-bankruptcy state. This reduces the shareholders' expected return on equity with risky projects. The point we make is that early compensation allows to transfer wealth from society to the coalition of shareholders and bank managers, and this is prevented by deferred compensation.

Second, while risk shifting incentives can also be curbed by capital requirements, this comes at the disadvantage of imposing an upper bound on the size of banks. Being strict on the timing of compensation allows the regulator to be softer on capital regulations without inducing risk-shifting (see also Thanassoulis (2014)). Thus, the potential downside of tight capital requirements that even projects with positive net present value will remain unfunded (credit crunch) can be mitigated by mandatory deferral of compensation. In this sense, our basic model makes a point in favor of payment regulation.

Third, however, we show that deferred compensation may backfire in a heterogenous banking sector when assuming that the number of safe projects is limited. As deferred compensation reduces the shareholders' risk appetite, the good bank (which can distinguish between safe and risky projects) may prefer safe instead of risky projects. As this deteriorates the remaining project mix in the economy, the bad bank (which cannot distinguish between project types) funds a larger percentage of risky projects. If the good bank has a comparative advantage in managing risky projects, deferred compensation leads to an inefficient allocation of safe and risky projects within the banking sector. It may then be better to accommodate risk-shifting in the

\footnotetext{
${ }^{4}$ Note that this distinction between 'early' and 'deferred' compensation is not identical to the one between fixed payments and bonuses; all that matters in our setting is whether compensation takes place before or after the default risk has materialized.

5 We will use the term risk-shifting when banks voluntarily fund risky projects even though their expected return is below the return of safe projects.
} 
good bank by allowing for early compensation, rather than by allowing for many projects by relaxing the capital equity ratio. We will get back to this from a regulatory point of view in the concluding section. ${ }^{6}$

Arguing that the legally required timing of compensation affects the shareholders' incentives for risk-shifting ultimately requires that the effect size is sufficiently large. It is thus important to note that regulations on bonuses an deferred compensation are not limited to CEOs, but extend to e.g. trading and investment banking. One of the main issues in the stockholders' meeting of Deutsche Bank in May 2015 was the fact that the bonuses paid to managers are five times higher than the dividends paid to shareholders, so that the question which part of remuneration is early or deferred seems clearly relevant not only from the managers', but also from the shareholders' point of view. Bell and Reenen (2014) find that two thirds of the large increase in the one percent highest salaries in the UK after 1999 can be attributed to the increase in banker's bonuses, and that this didn't even change after the financial crisis. Overall, it is no exception that remuneration exceeds $30 \%$ of shareholder equity, and the ratio sometimes exceeds even $80 \%$ of shareholder equity; something rarely observed in non-financial firms (Thanassoulis 2014).

\subsection{Relation to the literature}

Our paper is most directly related to literature on the impacts of deferred compensation and capital requirements on risk-shifting incentives, but also to the impact of bank managers' salaries on the incentives for risk-shifting, and to literature on interdependencies of banks' decisions in credit markets. As we do, most papers on deferred compensation consider the external agency problem between debtholders or the society on the one hand and shareholders on the other hand. Bolton et al. (2012) show that, while performance-based pay maximizes shareholder value, it is likely to induce excessive risk-taking from the debtholders' point of view. For mitigating these inefficiencies, they suggest tying bank managers' compensation not only to performance measures, but also to measures of default risk (see in a similar vein Bebchuk and Spamann 2010 and Edmans and Liu 2011). ${ }^{7}$ Many papers provide detailed suggestions for regulating bankers' pay, including the timing of deferred compensation schemes (Bebchuk and Fried 2010), tying CEO compensation to the CDS spread to account for the risk perceived by the market (Bolton et al. 2015), and charging deposit insurance premiums depending on the compensation structure (Phelan and Clement 2010). In Hakenes and Schnabel (2014), variable payments are beneficial since they induce effort of bank managers, but may also lead to risk-shifting. In case of potential public bail-outs, they find that a system of capped bonuses optimizes the trade-off between effort incentives and excessive risk-taking.

\footnotetext{
6 Our assumptions imply that the bad bank has no competitive advantage. Our main results, however, also hold when the bad bank has an advantage in handling safe projects as mandatory deferral of compensation and tight capital equity ratios may still (mis)allocate safe projects to the good bank.

7 This view corresponds to empirical evidence by Wei and Yermack (2011) who find that the CDS spread is decreasing in the percentage of CEO remuneration paid in inside debt.
} 
Another string of the literature on deferred compensation emphasizes that useful information may emerge over time, and that postponing payments allows to induce decisions contingent on this information. In Acharya et al. (2016) managers learn their types over time, so that the focus is on uncertainty rather than on asymmetric information. By contrast, deferring compensation allows to infer the agent's type in Inderst and Pfeil (2013). Learning comes at a cost as bank managers have a higher time preference than shareholders.

Also assuming that valuable information may emerge over time and that bank managers are impatient, Hoffmann et al. (2016) find that deferred compensation may even increase risk-shifting. There are mainly two reasons why their findings differ from ours: First, when confronted with a mandated minimum-deferral requirement, shareholders in their model may respond by using other instruments such as higher bonuses, while we consider exclusively early and late compensation. Second, they assume that shareholders need to pay rents to induce managers to exert risk-reducing effort. And as compensation regulation reduces the contract space, implementing high effort becomes more expensive. From a general perspective, Hoffmann et al. (2016) analyze the impact of compensation regulation on the second-best incentive contract in the principal-agent relationship between shareholders and managers (see also Hakenes and Schnabel (2014)). By contrast, our paper focuses on the impact of regulation on the external agency problem. While moral hazard models are appropriate for analyzing the conflict between shareholders and managers, models in the tradition of Aghion and Bolton (1987) are commonly used for investigating situations where two parties (here: shareholders and managers) have incentives to sign contracts that maximize their joint payoff at the expense of third parties (here: creditors or taxpayers). Following this tradition, it is instructive to neglect information problems between managers and shareholders, so that our approach is complementary to papers focusing on internal agency problems. ${ }^{8}$

In line with our findings, most papers on capital requirements argue that tighter standards reduce the risk appetite of financial institutions, but come at the cost of reduced lending (Thanassoulis 2014; Harris et al. 2017). In a rich model with a heterogeneous banking sector, Harris et al. (2017) show in addition that, by reducing banks' profits from socially valuable projects, fiercer competition from investors in public markets may increase risk-shifting by banks. In our model, increased competition with good banks increases the risk of the bad bank's lending portfolio.

Recently, the highly influential book by Admati and Hellwig (2014) calls for far higher capital equity ratios and argues that the argument that higher capital equity ratios would ultimately reduce bank lending is flawed. Calibrating a model on the private and social costs and benefit of bank equity, Miles et al. (2013) find that the socially optimal amount of equity is far higher than what is observed, and also far

\footnotetext{
8 Since we use a theoretical model to make our point, we do not go into the details of the empirical literature, which finds mixed evidence on compensation-induced risk-taking. While DeYoung et al. (2010), Suntheim (2010) and Cheng et al. (2015) find a connection between incentive pay and risk-taking, this is not supported in Fahlenbrach and Stulz (2011), for instance.
} 
higher than what is required under Basel III. ${ }^{9}$ Current proposals go beyond tighter capital requirements and include mandatory default insurance (Kashyap et al. 2008), reverse convertibles where debt is converted to equity in case the regulator assumes an increased default risk (Squam Lake Group 2009), flexible capital requirements depending on the price of Credit Default Swaps for debt (Hart and Zingales 2011) and so-called "Equity Liability Carriers" which are supposed to guarantee that financial institutions with limited liability can meet their obligations (Admati and Pfleiderer 2010). Bulow and Klemperer (2015) suggest so-called Equity Recourse Notes, which are a kind of debt whose payments are converted into equity in case of a large decrease in share prices. Some papers, however, argue that tight capital ratios may even increase risk-shifting (see the overviews in Bhattacharya et al. 1998 and Allen 2004). In Allen et al. (2011), banks can improve the quality of loans by monitoring and higher equity serves as a commitment device for monitoring.

While all papers mentioned so far restrict attention to either deferred compensation or capital regulation, there are only a few papers that analyze the interplay of compensation regulation and capital equity ratios. As we do, Eufinger and Gill (2016) neglect potential agency conflicts between shareholders and managers and focus on the shareholders' incentives to trigger risk-shifting via compensation schemes for bank managers. Risk-shifting incentives arise since debtholders are protected by deposit insurance if the debt is below a critical threshold. Payment schemes in Eufinger and Gill (2016) are not directly regulated, i.e. shareholders are free to choose between fixed wages (payments in case the safe project is chosen) and bonuses (payments contingent on the actual return of the risky project). But as shareholders anticipate that capital equity ratios are tighter in the latter case, their incentive to implement excessively high-powered compensation schemes disappears. Our model is less rich in this respect as the regulator in our model decides directly on the percentage of compensation that can only be paid out in case of no default. Eufinger and Gill (2016) do not consider a heterogenous banking sector and the possibility of a misallocation of risky project, which is a focus of our paper. As we do, Kolm et al. (2016) also argue that deferred compensation reduces risk-shifting. However, as it does not increase the inefficiently low incentives to search for risk-reducing investment strategies, tight capital regulations remain beneficial. Gete and Gomez (2016) argue that capital regulation is superior to direct compensation regulation as restricting variable pay does not only reduce risk-shifting incentives but also effort. The argument derived in our model that mandatory deferral of compensation outperforms tight capital ratios if and only if there are sufficiently many safe projects is, to the best of our knowledge, novel.

In our model, the advantage for shareholders when they pay early instead of deferred compensation for risky projects is that part of the (expected) compensation is effectively externalized to debtholders or society. Hence, risk-shifting incentives increase in the manager's salary. This relates our paper to a growing literature arguing that fiercer competition for bank managers leads to a more risky banking sector (Acharya et al. 2016; Thanassoulis 2012). The detrimental effects of competition are reinforced when the managers' talent is private information, as excessively high-powered incen-

\footnotetext{
9 Anginer et al. (2016) confirm empirically that payment schemes for executives setting high incentives for risk-taking are negatively correlated with the size of bank capital.
} 
tive contracts are then offered to reduce the rents of low types (Bannier et al. 2013; Bijlsma et al. 2012).

In our setting with a limited supply of safe projects, the good bank's portfolio choice influences the portfolio risk of the bad bank. And as the good bank's behavior depends on the regulation on deferred compensation and capital equity ratios, the regulatory regime leads to an interdependency between the two banks' portfolio risks. In this sense, our paper extends the literature on the interdependency of default risks from competition among banks (Broecker 1990; Nakamura 1993D; Riordan 1993; Shaffer 1998) and information sharing (Pagano and Jappelli 1993); see Harris et al. (2017) for competition between banks and outside investors.

Finally, our modelling of safe and risky projects draws on Feess and Hege (2012) who also assume that safe projects have higher expected returns, and who show that banks may nevertheless have incentives for risk-shifting if and only if the number of projects banks are allowed to fund via capital requirements exceeds a specific threshold. While they focus on the distinction between internal and external rating, they do not consider managers' compensation schemes, and hence also not the impact of (mandatory) deferral of compensation.

The remainder of the paper is organized as follows: Sect. 2 presents the model. In Sect. 3, we show that shareholders strictly prefer early compensation in case of positive default risk. Section 4 considers the scenario with an abundant supply of both project types. When extending the model to a limited number of projects in Sect. 5, we point out a potential drawback of deferred compensation. Our assumptions and the robustness of our model is discussed in Sect. 6. We conclude in Sect. 7.

\section{The model}

Banks and project types. In our model, there are two heterogenous banks, $i \in\{G, B\}$, each of which is run by a manager and owned by a shareholder maximizing his expected profits. All participants are assumed to be risk neutral. ${ }^{10}$ As detailed below, the good bank $\mathrm{G}$ has two advantages over the bad bank B; one with regards to the identification of project types and one concerning the expected return of risky projects. The two banks have identical and exogenously given equity endowments of $E$.

In line with standard arguments of the bank regulation literature (Acharya and Yorulmazer 2007; Acharya 2009), we assume that banks can fully diversify their idiosyncratic risk, so that only the contribution of each loan to the systematic risk exposure of the bank matters. We model this in the simplest way by assuming that there are two kinds of projects. One project type contains only idiosyncratic risk, and we refer to them as uncorrelated or safe projects. The other project type is exposed to systematic risk that cannot be diversified, and we refer to them as correlated or risky projects. The fraction of risky and safe projects in the economy is denoted by $\gamma$ and $1-\gamma$, respectively.

Costs of all projects are normalized to one, so that funds worth $n$ are needed to finance a portfolio of Lebesgue measure $n \leq 1$. Safe projects (projects "S") yield a

$\overline{10}$ In the concluding section, we briefly discuss what would change in case of risk-averse managers. 
gross return $X>2$ with probability $k \geq \frac{1}{2}$, and zero return with probability $1-k$. As these projects contain only fully diversifiable risk, the return of any measurable portfolio of $n$ safe projects is exactly $k n X$. We assume that the return of safe projects is independent of whether they are funded by the good or by the bad bank. This simplifies the analysis; but all that is required for our results is that the good bank has a comparative advantage in managing risky projects.

Risky projects (projects "R") have perfectly correlated gross returns, which are equal to $X$ with probability $\theta^{G}<k$ when funded by the good bank and with probability $\theta^{B} \in\left(\frac{1}{X}, \theta^{G}\right)$ when funded by the bad bank, and zero in the complementary event. Due to the perfect correlation of their returns, either the entire portfolio of risky projects fails or succeeds. Hence, bank $i$ 's gross return of a portfolio of $n$ risky projects will be $n X$ with probability $\theta^{i}$, and zero with probability $1-\theta^{i}$. Comparing risky and safe projects, both types of banks would prefer safe projects absent any default risk due to $\theta^{B}<\theta^{G}<k$. However, we assume that both banks will find it profitable to shift risks on outside creditors if they are at risk of default, i.e. we assume $k X-1<\theta^{B}(X-1)$. Furthermore, we assume that the share of risky projects in the economy is sufficiently large so as to rule out the case in which larger portfolios make the bad bank even less likely to default, i.e. we assume $(1-\gamma) k X<1$.

Assuming that projects are either perfectly correlated or uncorrelated is the simplest way to make our points, but the analysis could be extended to more and less correlation. ${ }^{11}$ For safe projects, examples are then AAA-rated loans or insurance policies for car accidents where risks are moderately correlated. For risky projects, one might think of subprime mortgage loans or start-up companies. On the one hand, default rates are highly correlated as they depend to a large degree on macroeconomic factors (for mortgage loans) and on the success of specific business models in related markets (see the burst of the dot-com bubble in he beginning of the century). On the other hand, however, good banks may be better at developing advisory capacity that reduces the failure risk of projects supported by their loan officers.

In addition to the higher expected return of risky projects, a second advantage of good banks concerns the information structure. While the bad bank cannot distinguish between project types $R$ and $S$, the good bank can identify them. Thus, the good bank can fund a portfolio with measures $n_{S}^{G}$ and $n_{R}^{G}$ of safe and risky portfolios, where the size of the portfolio will be bounded above by the regulator's capital equity requirement. As the bad bank's manager cannot distinguish between projects, the frequency of correlated and uncorrelated projects in the pool the bad bank picks from determines its portfolio composition. In Sect. 6, we discuss how our results change when assuming instead that it is the bad bank that can screen project types.

Summing up, our setting has the following implications: First, the default risk of banks is exclusively driven by risky projects, while safe projects effectively bolster a bank's equity, and hence reduce the default risk. Second, the good bank's advantage is twofold; it can distinguish between project types and it is superior at handling correlated projects. Assuming that both banks perform equally well for safe projects simplifies the analysis, but all we need is the reasonable feature that the good bank

11 Instead of assuming that all risky projects are either successful or fail, we could also assume that only an ex-ante uncertain fraction fails. We will get back to this possibility in Sect. 6. 
has a comparative advantage for risky projects. As a consequence, if risky projects are funded at all, this should be done by the good bank. ${ }^{12}$ The latter point will become important in Sect. 5 when we discuss potential advantages of allowing for (partially) early compensation.

Note that our assumptions imply that risky projects bear larger risk and have lower expected return, and would hence be strictly dominated by safe projects from the perspective of weakly risk-averse individual investors who are not (partially) protected by limited liability. This, however, is different when we consider the owners of banks with positive default risk: If safe projects had lower return, then shareholders would always prefer risky projects to benefit from the limited liability effect. Our assumptions are hence standard in models on banking regulation focusing on incentives for riskshifting.

Regulation. The regulator has two instruments to influence the portfolio size and its composition, capital requirements and mandatory deferral of (part of) the bank manager's compensation. For capital requirements, note first that, if the regulator was able to perfectly observe the banks' portfolios, it would be easy to implement the socially optimal choices by differentiating the capital equity ratios for risky and safe projects appropriately. To avoid this trivial solution, we consider the more realistic case in which the regulator cannot observe the projects chosen by banks. Thus, banks have the possibility to misreport risky projects as safe ones, so that differentiating the capital equity ratios is meaningless. We denote the single capital equity ratio by $b$. The banks' portfolio size is thus restricted by $n \leq \bar{n}=\frac{E}{b}$. Our assumption that the regulator does not differentiate the capital ratios between safe and risky projects is not only theoretically motivated by asymmetric information, but also resembles a clear-cut tendency in the current regulation. The financial crisis has shown that regulators can hardly assess the riskiness of banks' assets, and that banks will always be one step ahead in their creativity of camouflaging the risk of their portfolios. As a consequence, regulators define ratios more and more with respect to the banks' market capitalization (Core Tier-1 capital in Basel III) rather than by trying to make capital requirements dependent on the riskiness of the bank's assets. ${ }^{13}$

In addition to capital requirements, the regulator defines a minimum percentage $\lambda$ of the manager's compensation which can be paid out only after the return of projects has been realized, and if the bank is solvent (deferred compensation). Thus, we do not distinguish between fixed compensation and variable payments which are made contingent on new information; all that matters in our model is that early compensation allows to pay managers before it turns out whether risk-shifting leads to default. This implies that we define deferred compensation as a legal system where compensation

\footnotetext{
12 Our assumptions imply that the bad bank has no competitive advantage. Our main results, however, also hold when the bad bank has an advantage in handling safe projects as mandatory deferral of compensation and tight capital equity ratios may still (mis)allocate safe projects to the good bank.

13 Basel III has retained the possibility of internal rating for banks qualifying for the IRB approach. However, Basel III introduced a simple non-risk based leverage ratio to act as a credible supplementary measure to the risk-based capital requirements. The Basel Committee is of the opinion that this mitigates the risk of unrealistically low internal ratings to loans, and thereby also reduces the overall importance of the IRB-approach (Basel Committee on Banking Supervision 2015).
} 
is junior to all other claims in case of liquidation as the distinction between early and deferred compensation would otherwise be meaningless in our model. ${ }^{14}$ The question we are then most interested in is the interplay between capital equity ratios and deferred compensation, that is, the link between the socially optimal values of $b$ and $\lambda$.

Social Costs of Default Risk. With regards to the expected social costs from bank failure, we adopt a simple and rather general concept. Specifically, we define $B^{i}\left(n^{i}\right)$ as expected social cost when bank $i$ with a portfolio of size $n^{i}$ defaults with probability $1-\theta^{i}$, and if it is the only bank with positive bankruptcy risk. If both banks face positive default risk, expected social costs are denoted by $B^{G B}\left(n^{G}, n^{B}\right)$. We then impose as little structure as possible: First, we assume that $B^{G}(n), B^{B}(n)$ and $B^{2}(n):=B^{G B}(n, n)$ are all convex in $n$. Second, recall that, whenever there is a positive bankruptcy risk at all, then the bad bank's risk exposure is higher due to $\theta^{B}<\theta^{G}$. Thus, we assume that, for every $n, B^{G}(n)<B^{B}(n)<B^{G B}(n, n)$. This includes the (natural) case where, for identical portfolios, the actual bankruptcy costs in case of default are the same in both banks. If the difference between $\theta^{G}$ and $\theta^{B}$ is sufficiently large, it is also compatible with the case where the actual bankruptcy costs are higher in the good bank (for instance due to a higher loss in human capital).

Compensation schemes for managers. Recall that each bank is run by a single manager who decides on the bank's portfolio. We assume that managers are risk neutral and demand an expected compensation of $e$ to sign a contract in a bank. ${ }^{15}$ Most naturally, $e$ can be interpreted as the bank manager's exit option or opportunity cost. For the reasons discussed in the introduction, we assume that the good bank's shareholders can observe their banks' portfolios, so that there is no internal agency problem in our model. ${ }^{16}$ Each bank's shareholders can suggest a compensation scheme to a manager as a take-it-or-leave-it-offer.

As shareholders can observe the banks' portfolios, they can make payments contingent on those. Compensation contracts will thus specify (i) the compensation to be paid to the manager, potentially based on the portfolio observed by shareholders, ${ }^{17}$ and (ii) the percentages $\alpha \geq \lambda$ of this compensation that is paid out only after the project return has been realized and if the bank is not bankrupt. We will refer to this part as deferred compensation, and to the part $1-\alpha$ as early compensation. We assume $e<E$ as equity $E$ would otherwise not be sufficient to compensate the manager for his exit option $e$ with early payments only.

\footnotetext{
14 Note also that, if deferred compensation is made contingent on the return structure, then banks could circumvent regulations which implement a minimum fraction $\lambda$ of deferred compensation by defining a trigger which is unlikely to occur.

15 Assuming that managers are risk-averse would substantially complicate the analysis without adding much; see our discussion in the concluding section.

16 A similar result could be obtained by assuming that the returns of the two projects in case of success differ, which would allow shareholders to make salaries contingent on the outcome.

17 Recall that, as the bad bank cannot distinguish between projects, its portfolio composition is given by the fractions of risky and safe projects in the pool, potentially updated using the good bank's optimal project choice (see the discussion in the paragraph on Limited Supply of Projects below). Thus, these fractions are known to both the manager and shareholders.
} 
In our model, shareholders make the manager's compensation contingent on the bank's actual portfolio, while the regulator sets only $b$ and $\lambda$, but does not directly control the banks' portfolio choices. This might be challenged as salaries based on the manager's portfolio choice can only be legally enforced if the actual portfolio is verifiable; i.e. observability to shareholders is not sufficient for enforcement. Verifiability, however, theoretically enables the regulator to design mechanisms contingent on the actual portfolio, a possibility we exclude by assumption. To account for potential objections against this restriction, we have also considered an extended version of our model, in which we consider an information structure that makes it impossible for the regulator to directly control the banks' portfolio choices. In this extension, we still assume that the portfolio is observable, but can carry excessive risk for two reasons, poor behavior or bad luck. While shareholders are free to react on excessive risk levels whatever the reason, sanctions levied by the regulator will generally be upheld in court only if the regulator can provide enough substance that there was negligence or bad intention. In other words, while the level of observation might be the same for shareholders and the regulator, the basis on which they can take action will typically differ. All of our results are qualitatively unchanged. The advantage of this extended model is that the restrictions on the regulator's contract space emerge endogenously, but as this comes at the expense of a far more convoluted analysis, we only briefly summarize it in Sect. 6, and provide the model itself in an "Appendix" that is available on request.

Limited number of projects. We will consider two settings, one with an abundant supply of projects (Sect. 4), and one where the number of both project types is bounded (Sect. 5). In the first case, for any level of equity $E$ given, the only restriction on the banks' portfolios is the capital equity ratio $b$. This implies that the two banks' portfolio choices are independent from each other. In particular, due to the abundant supply of projects, the portfolio choice of the good bank does not affect the bad bank's portfolio which cannot distinguish between project types.

When projects are in limited supply, we assume that the good bank can use its informational advantage over the bad bank to attract its preferred project type. In our model, this is a natural assumption for two reasons: First, recall that the bad bank cannot distinguish among project types. Second, it will turn out that banks strictly prefer portfolios that consist of either only safe or risky projects to mixed portfolios. And as only the good bank can distinguish among projects, it can always slightly undercut the bad bank's offer to project owners.

Timing Summing up, the timing of the game is as follows:

1. The regulator announces $b$ and $\lambda$.

2. Shareholders offer contracts to managers who decide on acceptance.

3. The manager of the good bank chooses her portfolio.

4. The manager of the bad bank chooses her portfolio.

5. Shareholders observe the actual portfolios.

6. Early compensation is paid out according to the contracts designed in stage 2.

7. Nature determines the success or failure of risky projects.

8. Deferred compensation is paid out if the bank is solvent. 


\section{Optimal compensation contracts}

Each bank $i$ 's shareholders simultaneously choose the project portfolio $n_{S}^{i}, n_{R}^{i}$ that it will ask the manager to fund, the manager's contractual compensation $C_{i}$ and the share $\alpha_{i} \geq \lambda$ of that compensation to be deferred so as to maximize its ex-ante expected value. By assumption, managers in the good bank can distinguish between safe and risky projects. As the shareholder can observe the bank's actual portfolio, he can easily induce the manager to fund a specific portfolio by specifying zero compensation whenever the manager's project choice differs from the portfolio fixed in the contract. As managers in the bad bank cannot distinguish between project types, this bank's portfolio will be automatically determined by the composition of the project pool remaining after the good bank's lending decisions.

Hence, when shareholders make take-it-or-leave-it contract offers to managers, they only need to ensure that the manager accepts the contract (participation constraint), and the regulatory constraint for the percentage $\alpha_{i}$ of deferred compensation needs to be observed, i.e. $\alpha_{i} \geq \lambda$. The participation constraint requires in both banks that the manager's expected compensation is at least as large as their opportunity cost, and there will be a unique contractual compensation level $C_{i}$ for each choice of $n_{S}^{i}, n_{R}^{i}$ and $\alpha_{i}$ such that the participation constraint is binding. Note that specifying actual compensation to be equal to $e$ is only sufficient if the manager can be sure to receive the whole payment, that is, when all compensation is early or when there is no default risk. With positive default risk and partly deferred compensation, the compensation in the no-default state needs to be above $e$ in order to give the manager $e$ in expectation.

The following Lemma shows that, for a given portfolio $n_{S}^{i}, n_{R}^{i}$, either deferral of compensation does not matter or the bank strictly prefers early over deferred compensation, in which case $\alpha_{i}=\lambda$ is optimal. The Lemma presents conditions for each of these cases to arise.

Lemma 1 Suppose bank $i$ wants to fund $n_{S}^{i}$ safe and $n_{R}^{i}$ risky projects. Then:

(i) If $E+(k X-1) n_{S}^{i}-n_{R}^{i} \geq \frac{1-\lambda}{1-\left(1-\theta^{i}\right) \lambda}$, then the bank's expected value is, independently of $\alpha_{i}$, given by

$$
\pi_{i}\left(n_{S}^{i}, n_{R}^{i}\right)=E+(k X-1) n_{S}^{i}+\left(\theta^{i} X-1\right) n_{R}^{i}-e .
$$

(ii) If $E+(k X-1) n_{S}^{i}-n_{R}^{i}<\frac{1-\lambda}{1-\left(1-\theta_{i}\right) \lambda}$ e, then deferred compensation is as low as possible, $\alpha_{i}=\lambda$. The bank's expected value is

$$
\pi_{i}\left(n_{S}^{i}, n_{R}^{i}\right)=\theta^{i}\left[E+(k X-1) n_{S}^{i}+(X-1) n_{R}^{i}\right]-\frac{\theta^{i} e}{1-\left(1-\theta^{i}\right) \lambda} .
$$

Proof All proofs are relegated to the "Appendix".

In Case (i), the number of risky projects is so low that there is either no default risk at all or that, even in case of bankruptcy, the bank can satisfy all claims except (part of) the manager's deferred compensation. In other words, there is no risk for 
outsiders, and it is then impossible to externalize part of the risk to those outsiders. Then, the timing of compensation is irrelevant for banks: Paying the manager expected compensation $e$ imposes expected cost $e$ on the bank irrespective of $\lambda$.

In Case (ii), by contrast, the number $n_{R}^{i}$ of risky projects is so large and the part of the compensation paid out early so small that the bank defaults if the risky projects fail, and the bankruptcy assets are not sufficient to meet its obligations to outsiders. ${ }^{18}$ Then, shareholders maximize bank value by deferring only the legally binding part of the compensation. The reason is that early compensation protects the manager from the default risk, who hence weighs each Dollar of early compensation with one Dollar. Shareholders, by contrast, care about the payment only in the non-bankruptcy case, and thus benefit from deferring as little compensation as possible. In the extreme case where the manager is paid in full up front, paying the manager an amount of $e$ only imposes expected costs $\theta^{i} e$ on the bank. As the fraction $\lambda$ the bank needs to defer increases, the manager must be compensated for the foregone salary in case of default. This is reflected by the bank's expected costs of compensating the manager, $\frac{\theta^{i} e}{1-\left(1-\theta^{i}\right) \lambda}$, which is strictly increasing in $\lambda$. The intuition is that early compensation effectively externalizes part of the manager's compensation as the salary is no longer available for the bankruptcy assets. In this sense, the expression $e-\frac{\theta^{i} e}{1-\left(1-\theta^{i}\right) \lambda}=\frac{\left(1-\theta^{i}\right)(1-\lambda)}{1-\left(1-\theta^{i}\right) \lambda} e$ may be interpreted as the expected amount of money a bank saves in manager compensation by switching from a safe to a risky portfolio. Since this expression is strictly decreasing in $\lambda$, the bank can save less and less in manager compensation by introducing default risk as the regulation of manager compensation gets stricter.

Lemma 1 shows how the shareholders' preferences for early compensation depend on the portfolio, and this is independent on whether such a portfolio is chosen by a manager who can discriminate between project types (good bank) or not (bad bank). Thus, we do need to distinguish between the two bank types in Lemma 1.

Over all, the insight of Lemma 1 is that mandatory deferral of compensation reduces a bank's expected profit (2) if it is exposed to default risk due to the large number of risky projects in its portfolio, but leaves profit (1) unchanged if the bank relies mainly on safe projects. In other words, mandatory deferral of compensation makes risky projects less attractive and, thus, reduces banks' risk-taking incentives ceteris paribus.

In the following, we consider two settings: First, we assume that there is an abundance of both project types, which means that the two banks' shareholders' portfolio decisions are unlinked. The focus is thus completely on the relationship between mandatory deferral of compensation and capital requirements, whereas the heterogeneity of banks and potential scarcity of projects plays no role. In Sect. 4, we proceed to a model with limited supply of projects.

\section{Abundant supply of projects}

In this section, we assume that projects are in abundant supply, so that there is no interdependency between the two banks' portfolio decisions. We will see later that

\footnotetext{
18 Note that, if the bank defaults only because it can not (fully) pay the manager's deferred compensation, then we are back to Case (i).
} 
this case emerges as the limit of the case with a restricted number of projects where total supply of projects grows infinitely large. Considering the case with an abundant supply of projects first, however, sharpens the intuition on how the optimal regulation is influenced by bank competition for safe projects.

Equilibrium Project Choices. If projects are supplied in abundance, all that restricts banks' portfolios is capital-equity regulation. Capital requirements $b$ imply

$$
n=n_{S}+n_{R} \leq \frac{E}{b}
$$

that is, the maximum number of projects a bank can fund is $\bar{n}=\frac{E}{b}$. Let us first consider the good bank. As the manager can discriminate between project types, the problem is to choose $n_{S}^{G}$ and $n_{R}^{G}$ so as to maximize expected value given by (2) and (1) subject to (3). Straightforwardly, the capital requirement is always binding: Adding a marginal safe project to a given portfolio increases the value of a solvent bank by $(k X-1)$ and leaves a defaulting bank's value unchanged at zero, thus strictly increasing a bank's expected value.

Consider next the choice between risky and safe projects. Without default risk, shareholders always prefer safe projects due to their higher expected return, $k>\theta^{G}$. With default risk, however, shareholders face a trade-off between the higher return of safe projects and the fact that, in case of bankruptcy, the bank does not have enough equity to cover its liabilities. This means that, whenever the bank funds risky projects at all, it is profitable to replace even more safe projects with risky projects. This is the well-known risk-shifting problem: If equity is wiped out anyway in the case of failure, then increasing the risk even further keeps shareholders' downside risk constant, while improving gains on the upper tail of the distribution. As a consequence, shareholders will strictly prefer either risky or safe projects.

The choice between the two project types then depends on the number of projects $\bar{n}=\frac{E}{b}$ the bank is allowed to fund and the percentage of compensation that needs to be deferred, $\lambda$. The lower the number of projects the bank can fund, the lower is the benefit from the limited liability effect. Similarly, the higher $\lambda$, the less capital can indirectly be protected from bankruptcy by transferring it to the manager. Part ( $a$ ) of the following Proposition thus shows that shareholders of the good bank prefer safe projects if and only if $\bar{n}$ is sufficiently low and $\lambda$ sufficiently large, thereby confirming the intuition that tight capital equity ratios and mandatory deferral of compensation have comparable impacts on the incentives for excessive risk-taking. Besides, taking the partial derivative of the right hand side of the condition in Part (a (i)) of Proposition 1 with respect to $e$ shows that the maximum number of projects the regulator can allow without triggering risk-shifting by the good bank decreases in the manager's expected compensation $e$ - the higher the manager's compensation, the higher is the incentive to externalize part of the compensation to creditors via risk-shifting.

Part (a) of Proposition 1 summarizes the behavior of the good bank: ${ }^{19}$

19 While the impact of $\bar{n}$ resembles Lemma 1 in Feess and Hege (2012), our Proposition extends the analysis to include mandatory deferral of compensation and the interplay between both policy instruments. 
Proposition 1 Suppose that both project types are in abundant supply. Then, depending on the capital regulation $\bar{n}=\frac{E}{b}$ and the minimum fraction $\lambda$ of deferred compensation, banks' portfolios and default probabilities $\left(d^{i}\right)$ are:

(a) Good Bank G:

(i) $n_{S}^{G}=\bar{n}, n_{R}^{G}=0$ and $d^{G}=0, \quad$ if $\bar{n} \leq \hat{n}^{G}(\lambda):=\frac{E-\frac{1-\lambda}{1-\left(1-\theta_{G}\right) \lambda} e}{1-\frac{k-\theta_{G}}{1-\theta_{G}} X}$;

(ii) $n_{S}^{G}=0, n_{R}^{G}=\bar{n}$ and $d^{G}=1-\theta^{G}$, otherwise.

(b) Bad Bank B: $n_{S}^{B}=(1-\gamma) \bar{n}, n_{R}^{B}=\gamma \bar{n}$ and

$$
d^{b}=\left\{\begin{array}{l}
0, \quad \text { if } \bar{n} \leq \hat{n}^{B}:=\frac{E-e}{1-(1-\gamma) k X} \\
1-\theta^{B}, \text { otherwise }
\end{array}\right.
$$

(c) Comparison of Banks: For every $\lambda \in[0,1]$ there exists a $\hat{\gamma}(\lambda) \in(0,1)$ such that $\hat{n}^{G}(\lambda)<\hat{n}^{B}$ if and only if $\gamma<\hat{\gamma}(\lambda)$.

Turning next to the bad bank in part (b) of the Proposition, recall that managers cannot discriminate between the two project types, so that risk-shifting is no issue. As the good bank does, the bad bank will always fund as many projects as possible, i.e. $n^{B}=\bar{n}=\frac{E}{b}$. To see this, just note that the expected return of both project types is positive, and that the shareholder in addition benefits from the limited liability effect in case of bankruptcy. Due to the law of large numbers, the fractions of risky and safe projects in the bad bank's portfolio are thus always $\gamma$ and $1-\gamma$, respectively.

To see the reason for part (c), recall first that the bad bank cannot identify projects, so that their default risk is purely driven by the portfolio size and the exogenously given fraction $\gamma$ of risky projects. If most projects are safe ( $\gamma$ low), the bad bank will never default even if it funds a large portfolio. But if most projects are risky ( $\gamma$ close to 1 ), the bad bank will be at risk of default whenever their portfolio is larger than $E-e$, the difference between its equity and the manager's compensation. By contrast, the good bank's default risk is driven by its choice between all-safe and all-risky portfolios, which in turn depends on the maximum portfolio size permitted by capital regulation. Irrespective of $\lambda$, the good bank prefers safe projects for very small portfolios, but risky projects even for permitted portfolio sizes below $E-e$ due to the externality it imposes on creditors. Hence, irrespective of $\lambda$, it is always possible to find pairs of $\gamma$ and $\bar{n}$ such that the good bank is at risk of default but the bad bank is not, and vice versa.

Optimal Regulation. Recall that social welfare in our model is just the sum of net returns of all projects, reduced by social costs of default. With the equilibrium project choices derived in Proposition 1, we get: ${ }^{20}$

$\overline{20}$ Superscript "A" denotes the setting where safe projects are in abundant supply. 


$$
\begin{aligned}
& S W^{A}(\bar{n}) \\
& \quad= \begin{cases}S W_{i}^{A}(\bar{n}):=\left[\left((2-\gamma) k+\gamma \theta^{B}\right) X-2\right] \bar{n}, & \text { if } \bar{n} \leq \min \left\{\hat{n}_{G}(\lambda), \hat{n}_{B}\right\} ; \\
S W_{i i}^{A}(\bar{n}):=\left[\left((2-\gamma) k+\gamma \theta^{B}\right) X-2\right] \bar{n}-B^{B}(\bar{n}), & \text { if } \hat{n}_{B} \leq \bar{n}<\hat{n}_{G}(\lambda) ; \\
S W_{i i i}^{A}(\bar{n}):=\left[\left((1-\gamma) k+\theta^{G}+\gamma \theta^{B}\right) X-2\right] \bar{n}-B^{G}(\bar{n}), & \text { if } \hat{n}_{G}(\lambda) \leq \bar{n}<\hat{n}_{B} ; \\
S W_{i v}^{A}(\bar{n}):=\left[\left((1-\gamma) k+\theta^{G}+\gamma \theta^{B}\right) X-2\right] \bar{n}-B^{G B}(\bar{n}, \bar{n}), & \text { if } \bar{n}>\max \left\{\hat{n}_{G}(\lambda), \hat{n}_{B}\right\} .\end{cases}
\end{aligned}
$$

The first line captures the case without default risk, i.e. where shareholders of the good bank prefer safe projects, and where $\bar{n}=\frac{E}{b}$ is so low that the bad bank is not driven into bankruptcy even when risky projects fail. In the second line, the good bank's shareholder still prefers safe projects, but the capital equity ratio is not tight enough to avoid the default of the bad bank in case risky projects fail. The third line deals with the opposite case: While the good bank's shareholder now prefers risky projects, the capital equity ratio is tight enough to certainly avoid the default of the bad bank. Note that a switch from the second to the third line requires that $\lambda$ decreases, since the good bank's shareholder's incentive for risk-shifting decreases in $\lambda$, while the bad bank's bankruptcy risk only depends on $\bar{n}$, i.e. on the capital equity ratio. The fourth line, finally, represents the case where both banks default if risky projects fail.

For a given capital regulation $\bar{n}$, it is easy to check that $S W_{i}^{A}(\bar{n})>\max \left\{S W_{i i}^{A}(\bar{n})\right.$, $\left.S W_{i i i}^{A}(\bar{n})\right\} \geq \min \left\{S W_{i i}^{A}(\bar{n}), S W_{i i i}^{A}(\bar{n})\right\}>S W_{i v}^{A}(\bar{n})$ holds: As safe projects have higher expected return and avoid any bankruptcy risk, it is better that the good bank has an allsafe portfolio. Furthermore, social welfare in cases (ii) or (iii) where just one bank is risk-free cannot be ranked without further assumptions as this depends on the portfolio mix in the bad bank (i.e. on $\gamma$ ). Finally, for a given number of funded projects $n$, welfare is clearly lowest when both banks face positive default risk.

When shareholders implement their profit-maximizing portfolios, however, they impose two kinds of externalities: First, due to limited liability, they don't take into account their creditors' losses in case of default. Second, the additional social cost of default $B_{i}(\cdot)$ are a negative externality. Hence, banks choose their privately optimal project portfolios characterized in Proposition 1, although all-safe portfolios are always socially optimal.

The analysis of the banks' portfolio choices in Proposition 1 has shown that, when the regulator wants to implement a risk-free banking sector, he needs to impose tight restrictions, so that the banking sector will be small. Thus, there is a trade-off between inducing the good bank to make more efficient project choices and permitting more projects to be carried out in the economy (recall that, neglecting bankruptcy costs, risky projects also provide positive expected net return). This trade-off is illustrated in Fig. 1, which displays social welfare for different numbers of projects banks are permitted to fund when $\hat{n}^{G}(\lambda)<\hat{n}^{B}$ (i.e., $\gamma<\hat{\gamma}(\lambda)$ ). The linear function represents the case without bankruptcy risk $\left(S W_{i}^{A}(\bar{n})\right)$ in which each additional project just adds its expected net return $k X-1>0$ (in the good bank) and $\gamma(k X-1)+(1-\gamma)\left(\theta^{B} X-1\right)$ (in the 


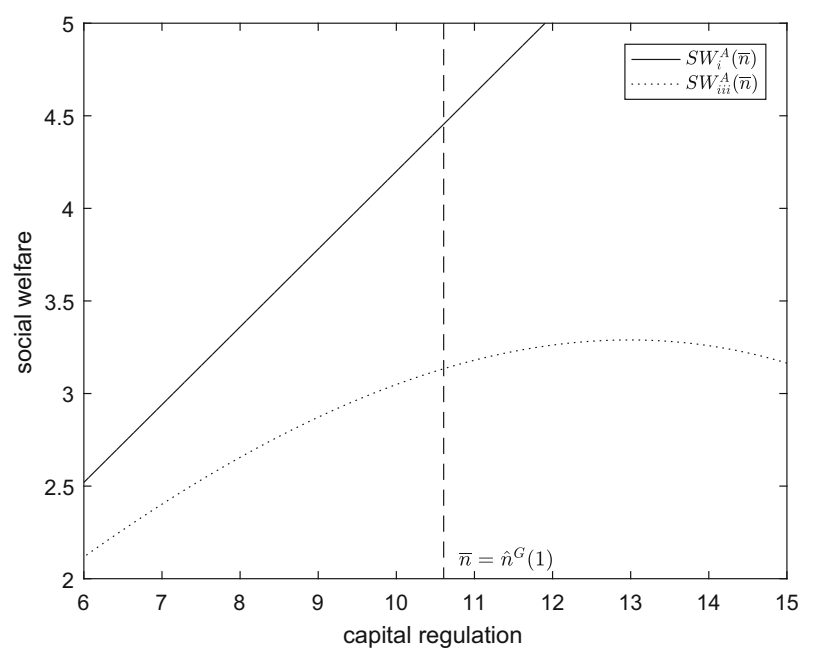

Fig. 1 Abundant supply of projects: maximum mandatory deferral of compensation in a risk-free banking sector. For $n \leq \hat{n}^{G}(\lambda)$, both banks are free from default risk, and social welfare is given by the solid line. For $n>\hat{n}^{G}(\lambda)$, the good bank prefers risky projects, and social welfare is given by the dotted concave curve. The optimal capital regulation is $n=\hat{n}^{G}(\lambda)$. Increasing mandatory deferral of compensation $\lambda$ shifts the threshold $\hat{n}^{G}(\lambda)$ (vertical dashed line) to the right, which is social welfare enhancing as the regulator can allow the good bank to fund more projects while avoiding risk-shifting incentives

bad bank) to social welfare. By contrast, the curve representing $S W_{i i i}^{A}(\bar{n})$ is concave due to the social cost of default. ${ }^{21}$

Figure 1 displays a situation where social welfare is highest when the regulator restricts the number of projects so that the banking sector is risk free (case (i) in equation (4), represented by the solid line), i.e. $\bar{n}=\min \left\{\hat{n}^{G}(\lambda), \hat{n}^{B}\right\}$, compared to a setting where only the good bank faces positive bankruptcy risk (case (iii) in equation (4), represented by the dotted curve). ${ }^{22}$ Recall that the case where only the good bank faces default risk is the one where $\gamma$ is low, i.e. where the mixed portfolio in the bad bank contains a large fraction of safe projects. In order to increase the number of projects for which the good bank still prefers safe projects, it is then optimal to demand full deferral of compensation, $\lambda=1$. In Fig. 1 , this moves the threshold $\hat{n}^{G}(\lambda)$, represented by the dashed vertical line, to the right. Thus, whenever the regulator wants to keep the entire banking sector risk free, mandatory deferral of full compensation is optimal as it allows for a larger banking sector without triggering risk-shifting in the good bank.

If the capital ratio required to avoid risk-shifting in the good bank is very strict, however, the regulator may accommodate risk-shifting in order to increase the size of the banking sector. In this case, the optimal capital regulation $\bar{n}=\frac{E}{b}$ is driven by the trade-off between bank size and social cost of default rather than by the threshold implied by $\lambda$. In order to discuss this case, it will prove useful to introduce some

\footnotetext{
21 The same holds for $S W_{i i}^{A}(\bar{n})$ where the good instead of the bad bank faces the positive default risk.

22 The parameter values and functions in the numerical examples that all figures in the paper are based on are available upon request.
} 
additional notation. For all $j \in\{i i, i i i, i v\}$, let

$$
\bar{n}_{j}^{A}:=\operatorname{argmax} S W_{j}^{A}(\bar{n})
$$

denote the unique peaks of each of the concave functions the social welfare function is made up of.

To exclude the uninteresting case, assume that it is never optimal for the regulator that both banks face positive default risk:

Assumption 1 If $\gamma \leq \hat{\gamma}(1)$, then $S W_{i v}^{A}\left(\bar{n}_{i v}^{A}\right)<\max \left\{S W_{i}^{A}\left(\hat{n}_{G}(1)\right), S W_{i i i}^{A}\left(\min \left\{\bar{n}_{i i i}^{A}\right.\right.\right.$, $\left.\left.\left.\hat{n}^{B}\right\}\right)\right\}$.

If $\gamma>\hat{\gamma}(1)$, then $S W_{i v}^{A}\left(\bar{n}_{i v}^{A}\right)<\max \left\{S W_{i}^{A}\left(\hat{n}^{B}\right), S W_{i i}^{A}\left(\min \left\{\bar{n}_{i i}^{A}, \hat{n}^{G}(1)\right\}\right)\right\}$.

Then, the optimal mix of capital requirement and regulation of managerial compensation can be characterized as follows:

Proposition 2 Suppose that both project types are in abundant supply and that Assumption 1 holds. If $\gamma \leq \hat{\gamma}(1)$, then:

(1a) If $S W_{i i i}^{A}\left(\min \left\{\bar{n}_{i i i}^{A}, \hat{n}^{B}\right\}\right)<S W_{i}^{A}\left(\hat{n}^{G}(1)\right)$, then the unique optimal regulation is $\lambda=1$ and $\bar{n}=\hat{n}^{G}(1)$.

(1b) If $\hat{n}^{B}<\bar{n}_{i i i}^{A}$ and $S W_{i}^{A}\left(\hat{n}^{G}(1)\right) \leq S W_{i i i}^{A}\left(\hat{n}_{B}\right)$, then the optimal regulation is $\bar{n}=\hat{n}^{B}$ and any $\lambda$.

(1c) Otherwise, the optimal regulation is $\bar{n}=\bar{n}_{\text {iii }}^{A}$ and any $\lambda$.

If $\gamma>\hat{\gamma}(1)$, then:

(2a) If $S W_{i i}^{A}\left(\min \left\{\bar{n}_{i i}^{A}, \hat{n}^{G}(1)\right\}\right)<S W_{i}^{A}\left(\hat{n}^{B}\right)$, then optimal regulation is $\bar{n}=\hat{n}^{B}$ and any $\lambda$.

(2b) If $\hat{n}^{G}(1)<\bar{n}_{i i}^{A}$ and $S W_{i}^{A}\left(\hat{n}^{B}\right) \leq S W_{i i}^{A}\left(\hat{n}^{G}(1)\right)$, then the unique optimal regulation is $\lambda=1$ and $\bar{n}=\hat{n}^{G}(1)$.

(2c) Otherwise, the optimal regulation is $\bar{n}=\bar{n}_{i i}^{A}$ and any $\lambda \in\left\{\lambda: \bar{n}_{i i}^{A} \leq \hat{n}^{G}(\lambda)\right\}$.

Proof Follows immediately from above.

In cases (1a) to (1c), the critical $\bar{n}$ above which the good bank switches to an all-risky portfolio, even for $\lambda=1$, is lower than that above which the bad bank faces positive bankruptcy risk (i.e. $\hat{n}^{G}(1) \leq \hat{n}^{B}$ ). Thus, given our assumption that the regulator will never implement a fully risky banking sector, he is left with three possibilities: In case (1a), it is optimal to keep the banking sector risk-free. As mentioned before, it is then optimal to set $\lambda=1$ as this minimizes the good bank's risk-shifting incentives; thereby allowing to increase $\bar{n}$ up to $\hat{n}^{G}(1)$. In case (1b), the regulator tolerates risk-shifting by the good bank, and $\bar{n}$ is thus given by the maximum number of projects the bad bank can fund without risk of default. Mandatory deferral of compensation is then meaningless as the good bank funds an all-risky portfolio anyway, while the bad bank cannot distinguish between project types. However, if $\gamma$ is so high that the bad bank faces default risk only for a very large number of projects, then the optimal $\bar{n}$ is no longer given by $\bar{n}=\hat{n}^{B}$, but depends on the (convex) bankruptcy costs in the good bank, as accounted for in case (1c). 
The cases (2a) to (2c) can be interpreted analogously, with the only difference that $\hat{n}^{G}(1)>\hat{n}^{B}$, so that, in case of a risky banking sector, the bad bank faces the risk of default. This is the case if the frequency of safe projects in the economy is low, as this frequency determines directly the risk exposure of the bad bank, but leaves the risk-shifting incentives of the good bank unchanged. ${ }^{23}$

Summing up, the regulator decides between a small banking sector without default risk or a larger, but risky banking sector. Our analysis with an abundant availability of the socially preferable safe projects then yields two main insights: First, mandatory deferral of compensation and tight capital requirements are substitutes with respect to the incentives for risk-shifting. Second, whenever the regulator wants to avoid riskshifting, mandatory deferral of compensation is superior to tighter capital requirements as it allows banks to fund more socially valuable projects.

\section{Limited number of projects}

Equilibrium Project Choices. We now turn to our second setting, in which the numbers of both safe and risky projects in the economy are limited. Let $N_{S}$ and $N_{R}$ be the total number of safe and risky projects, respectively, in the economy. To avoid tedious and economically uninteresting case distinctions, let us assume that $\bar{n}<\min \left\{N_{S}, N_{R}\right\}$, so that the good bank will still fund an all-safe or all-risky portfolio.

The fact that the number of both project types is limited does not necessarily exclude that both banks can fund all-safe or all-risky portfolios; it just means that the good bank's portfolio choice influences the pool the bad bank can fish in, and hence its portfolio. To make this point as simple as possible, we assume that the good bank can first pick its portfolio. The fraction of risky projects in the economy after the good bank has made its choice, and hence also the fraction of risky projects in the bad bank's portfolio, is now affected by the good bank's behavior. Denote this fraction by $\gamma_{S}(\bar{n}):=\frac{N_{R}}{N_{R}+N_{S}-\bar{n}}$ when the good bank has picked an all-safe portfolio, and by $\gamma_{R}(\bar{n}):=\frac{N_{R}-\bar{n}}{N_{R}+N_{S}-\bar{n}}$ when the good bank has picked an all-risky portfolio of size $\bar{n}$. Note that the bad bank's portfolio is always affected by the good bank's portfolio choice except in the implausible sequence where the bad bank chooses its entire portfolio first (in this uninteresting case, nothing changes compared to the case with an abundant supply of projects).

For later reference, note that $\gamma_{S}(\cdot)$ is increasing and $\gamma_{R}(\cdot)$ is decreasing in $\bar{n}$, and $\gamma_{S}(0)=\gamma_{R}(0)$. Furthermore, $\gamma_{S}(\cdot)\left(\gamma_{R}(\cdot)\right)$ approaches the initial share $\gamma$ of risky projects in the economy from above (below) as the total supply of projects $N_{R}+N_{S}$ grows large. In other words, the case where projects are in abundant supply discussed

\footnotetext{
23 Note that the regulator's decision problem would be straightforward if he could differentiate capital ratios between good and bad banks. In this case, the optimal regulation of one type of bank would no longer be related to the other type's default probability. Furthermore, the interior solution $\bar{n}_{i i i}^{A}$ would be bank specific, too. For instance, in case (1b) of 2, the optimal bank specific regulation would be $\hat{n}^{B}$ for the bad and the interior welfare maximizing regulation for the good bank, in which the good bank is at risk of default. This is a strict welfare improvement to the optimal regulation in case (1b) of Proposition 2. Over all, welfare is weakly higher if the regulator can differentiate between types of banks.
} 
in Sect. 4 is the limit case of this analysis where total supply of projects grows infinitely large.

As the fraction of risky projects in the economy when the bad bank makes its choice depends on the good bank's choice, so does the maximum number $\hat{n}^{B}$ of projects the bad bank can be allowed to fund without incurring any default risk. We denote this maximum number by $\hat{n}_{S}^{B}$ or $\hat{n}_{R}^{B}$, depending on whether the good bank has picked an all-safe or an all-risky portfolio, respectively. These maximum risk-free portfolio sizes for the bad bank are implicitly given by ${ }^{24}$

$$
\begin{aligned}
& \hat{n}_{S}^{B}=\frac{E-e}{1-\left(1-\gamma_{S}\left(\hat{n}_{S}^{B}\right)\right) k X} \\
& \hat{n}_{R}^{B}=\frac{E-e}{1-\left(1-\gamma_{R}\left(\hat{n}_{R}^{B}\right)\right) k X}
\end{aligned}
$$

Depending on the capital regulation, $\bar{n}=\frac{E}{b}$ and the mandatory percentage deferral of compensation, $\lambda$, the equilibrium allocations of projects and default risks are now given by the following Proposition:

Proposition 3 Suppose both project types are in limited supply. Then, banks' portfolios $n_{S}^{i}, n_{R}^{i}$, and default probabilities $d^{i}$ are:

(i) $n_{S}^{G}=\bar{n}, n_{R}^{G}=0, n_{S}^{B}=\left(1-\gamma_{S}(\bar{n})\right) \bar{n}, n_{R}^{B}=\gamma_{S}(\bar{n}) \bar{n}$ and $d^{G}=d^{B}=0$ if $\bar{n} \leq \min \left\{\hat{n}^{G}(\lambda), \hat{n}_{S}^{B}\right\}$.

(ii) $n_{S}^{G}=\bar{n}, n_{R}^{G}=0, n_{S}^{B}=\left(1-\gamma_{S}(\bar{n})\right) \bar{n}, n_{R}^{B}=\gamma_{S}(\bar{n}) \bar{n}, d^{G}=0$ and $d^{B}=1-\theta^{B}$ if $\hat{n}_{S}^{B}<\bar{n} \leq \hat{n}^{G}(\lambda)$.

(iii) $n_{S}^{G}=0, n_{R}^{\bar{G}}=\bar{n}, n_{S}^{B}=\left(1-\gamma_{R}(\bar{n})\right) \bar{n}, n_{R}^{B}=\gamma_{R}(\bar{n}) \bar{n}, d^{G}=1-\theta^{G}$ and $d^{B}=0$ if $\hat{n}^{G}(\lambda)<\bar{n} \leq \hat{n}_{R}^{B}$.

(iv) $n_{S}^{G}=0, n_{R}^{G}=\bar{n}, n_{S}^{B}=\left(1-\gamma_{R}(\bar{n})\right) \bar{n}, n_{R}^{B}=\gamma_{R}(\bar{n}) \bar{n}, d^{G}=1-\theta^{G}$ and $d^{B}=1-\theta_{B}$ if $\bar{n} \geq \max \left\{\hat{n}_{G}(\lambda), \hat{n}_{R}^{B}\right\}$

where $\hat{n}_{S}^{B}$ and $\hat{n}_{R}^{B}$ are given by (5) and (6), and $\hat{n}_{S}^{B}<\hat{n}_{R}^{B}$.

In cases (i) and (ii), the good bank prefers safe projects, so that the critical $\bar{n}$ that triggers a positive bankruptcy risk in the bad bank is low (the remaining fraction of safe projects in the economy is below $1-\gamma$ ). Then, case (i) captures the situation where $\bar{n}$ is so low that the bad bank faces no default risk, whereas it fails in case (ii) whenever risky projects fail. Note that this case requires also that $\bar{n} \leq \hat{n}^{G}(\lambda)$, since the good bank would otherwise prefer risky projects.

In cases (iii) and (iv), the good bank funds an all-risky portfolio. In case (iii), only the good bank faces bankruptcy risk, which requires that $\hat{n}^{G}(\lambda)<\bar{n} \leq \hat{n}_{R}^{B}$. Finally, both banks face positive bankruptcy risk in case (iv).

As an illustration, Fig. 2 displays the threshold capital regulations for the cases discussed in Proposition 3 as functions of the share $\gamma$ of risky projects in the original pool of projects. The solid horizontal lines are $\hat{n}^{G}(1)$ (the upper line) and $\hat{n}^{G}(0)$ (the

$\overline{24}$ To be exact, since $n_{R}^{B}$ may not be well defined according to (6), let us define it in this case to be infinity. 


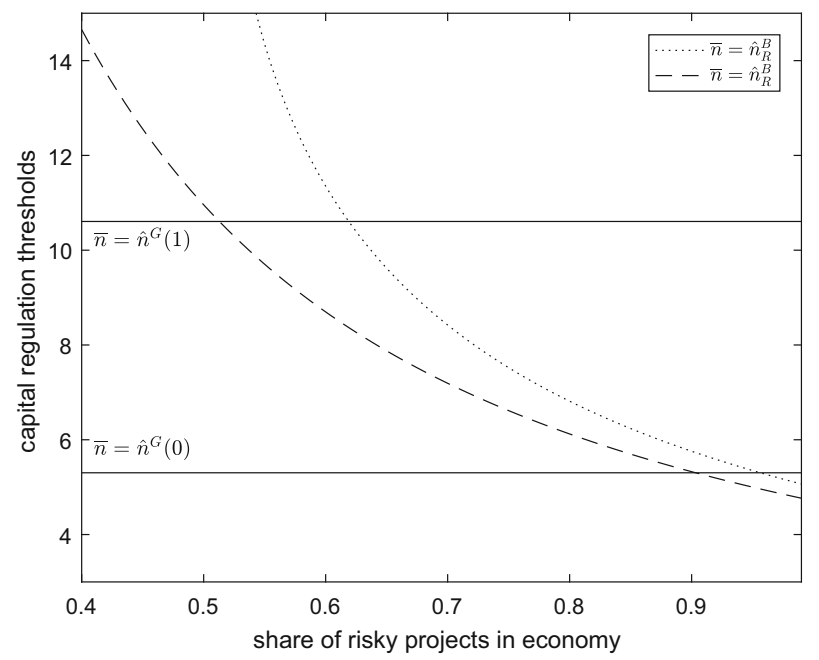

Fig. 2 Existence of cases discussed in Proposition 3. Capital regulation above which the bad bank is at risk of default given that good bank funds all-risky (dotted curve, $\hat{n}_{R}^{B}$ ) and all-safe (dashed curve, $\hat{n}_{S}^{B}$ ) portfolio, respectively

lower line). Both $\hat{n}^{G}(1)$ and $\hat{n}^{G}(0)$ are independent of $\gamma$, and the higher the share of compensation that needs to be deferred, the larger is the portfolio size $\bar{n}$ beyond which the good bank wants to engage in risk shifting.

The dashed curve represents the threshold portfolio size $\hat{n}_{S}^{B}$ beyond which the bad bank has positive default risk when the good bank funds an all-safe portfolio. If $\gamma$ is low, this threshold is above the good bank's threshold for risk shifting even if all compensation must be deferred. This means that the bad bank will never be at risk of default for portfolio sizes for which the good bank prefers safe projects. For larger $\gamma$, however, the dashed curve falls below the upper solid line, and the area above the dashed curve and below the solid line then represents case (ii) in Proposition 3. In this case, the bad bank is at risk of default, while the good bank still does not have incentives for risk shifting if all compensation must be deferred. If $\gamma$ increases further, then the bad bank may even be at risk of default for portfolio sizes that wouldn't induce the good bank to fund an all-risky portfolio absent any mandatory deferral of compensation.

Similarly, the dotted curve represents the threshold portfolio size $\hat{n}_{R}^{B}$ beyond which the bad bank has positive default risk when the good bank funds an all-risky portfolio. For small $\gamma$, there are some portfolio sizes above $\hat{n}^{G}(\lambda)$ but below the dotted curve such that the good bank will fund an all-risky portfolio whereas the bad bank is free from default risk. For higher $\gamma$, however, the bad bank will be at risk of default whenever the good bank has incentives for risk shifting. Again, the level of $\gamma$ beyond which the latter case applies, is decreasing in $\lambda$.

Furthermore, recall that the fraction of risky projects in the bad bank's portfolio is higher (lower) than in the economy if the good bank funds safe (risky) projects. Thus, in case the good bank picks risky projects, the capital regulation required to avoid any bankruptcy risk in the bad bank can be less strict, i.e. $\bar{n}$ can be larger. This 
is represented by the dotted line in Fig. 2. This endogeneity of the bad bank's default risk and its impact on the socially optimal percentage of deferred compensation is the main point we wish to make when we now turn to the optimal regulation.

Optimal Regulation. From the case distinction describing the banks' portfolios and default risks, we immediately obtain the following social welfare:

$$
\begin{aligned}
& S W^{L}(\bar{n}) \\
& \quad= \begin{cases}S W_{i}^{L}(\bar{n}):=\left[\left(\left(2-\gamma_{S}(\bar{n})\right) k+\gamma_{S}(\bar{n}) \theta^{B}\right) X-2\right] \bar{n}, & \text { in case (i) of Proposition (3); } \\
S W_{i i}^{L}(\bar{n}):=\left[\left(\left(2-\gamma_{S}(\bar{n})\right) k+\gamma_{S}(\bar{n}) \theta^{B}\right) X-2\right] \bar{n}-B_{B}(\bar{n}), & \text { in case (ii) of Proposition (3); } \\
S W_{i i i}^{L}(\bar{n}):=\left[\left(\left(1-\gamma_{R}(\bar{n})\right) k+\theta^{G}+\gamma_{R}(\bar{n}) \theta^{B}\right) X-2\right] \bar{n}-B_{G}(\bar{n}), & \text { in case (iii) of Proposition (3); } \\
S W_{i v}^{L}(\bar{n}):=\left[\left(\left(1-\gamma_{R}(\bar{n})\right) k+\theta^{G}+\gamma_{R}(\bar{n}) \theta^{B}\right) X-2\right] \bar{n}-B_{G B}(\bar{n}, \bar{n}), & \text { in case (iv) of Proposition (3. }\end{cases}
\end{aligned}
$$

Compared to the case of abundant supply of projects, the limited supply of projects sets higher incentives for the regulator to accommodate risk-shifting by the good bank. To see this, just recall that the percentage of risky projects in the bad bank increases when the good bank funds an all-safe portfolio. Compared to the setting with an abundant supply of projects, this introduces a countervailing social benefit of the good bank's risk shifting. If this benefit is sufficiently large, risk shifting by the good bank may even be socially superior to keeping the banking sector free from default risk for the same given portfolio size.

Furthermore, this effect reduces the maximum number of projects the bad bank can fund without default risk, and hence requires tougher capital equity ratios if the regulator wants to keep the entire banking sector risk free. By contrast, if the good bank funds an all-risky portfolio, then the percentage of safe projects in the bad bank's portfolio increases, and the regulator can allow for more projects even when he wants to keep the bad bank risk free. As a consequence, it may now be better to trigger risk-shifting by the good bank even in cases where this was inferior in the setting with an abundant supply of projects. Recalling that the good bank is superior in managing risky projects as expressed by $\theta^{G}>\theta^{B}$, this case is not far-fetched.

From the previous analysis, we know that, when the regulator wants to induce riskshifting by the good bank in order to improve the quality of the bad bank's portfolio, there are two possibilities; he can either increase $\bar{n}$ or reduce $\lambda$. Which of the two instruments is superior depends on the situation: Suppose first that the regulator wants to induce risk-shifting by the good bank, but without jeopardizing too many projects, for instance because bankruptcy costs are highly convex in $n$. Then, it is better to trigger risk-shifting in the good bank by reducing $\lambda$. Thus, by contrast to the case with an abundant supply of projects, full mandatory deferral of compensation is now no longer a weakly dominant choice for the regulator. Second, consider the case where $\gamma$ is so high that the bad bank has zero default risk even when the number of projects is high. Then, the regulator does not want to reduce the number of projects in the economy. Thus, risk-shifting in the good bank can be triggered by lax capital regulations, and there is no benefit from reducing $\lambda$. 
Let us now move more formally to the welfare comparison of the different cases. Just like in the previous case, let us, for all $j \in\{i, i i, i i i, i v\}$, define

$$
\bar{n}_{j}^{L}:=\operatorname{argmax} S W_{j}^{L}(\bar{n})
$$

as the unique peaks of each of the concave functions the social welfare function is made up of. Note that, due to the impact of the good bank's choice on the project pool available to the bad bank, $S W_{i}^{L}(\cdot)$ is also concave.

In order to further streamline the discussion, Assumption 2 rules out some of the less relevant cases:

Assumption 2 (a) $\hat{n}^{G}(1)<\bar{n}_{i}^{L}$ and $\hat{n}^{G}(0)<\hat{n}_{R}^{B}$.

(b) $S W_{i i}^{L}\left(\bar{n}_{i i}^{L}\right)<\max \left\{S W_{i}^{L}\left(\hat{n}_{B}^{S}\right), S W_{i i i}^{L}\left(\hat{n}_{G}(0)\right)\right\}$.

(c) $S W_{i v}^{L}\left(\bar{n}_{i v}^{L}\right)<\max \left\{S W_{i}^{L}\left(\min \left\{\hat{n}^{G}(1), \hat{n}_{S}^{B}\right\}\right), S W_{i i i}^{L}\left(\max \left\{\hat{n}^{G}(1), \hat{n}_{R}^{B}\right\}\right)\right\}$.

Part (a) of Assumption 2 ensures that the trade-off between the benefits from funding more projects and protecting society from banks' default risk exists for any $\lambda$ : If, by contrast, $\bar{n}_{i}^{L} \leq \hat{n}^{G}(1)$, then the social welfare maximizing regulation would simply be $\lambda=1$ and $\bar{n}=\bar{n}_{i}^{L}$. Similarly, if $\hat{n}_{R}^{B} \leq \hat{n}^{G}(0)$, there wouldn't exist any regulation such that the good bank has a positive default risk but the bad bank has not.

Parts (b) and (c) of Assumption 2 ensure that it is never efficient that either both or only the bad bank banks face positive bankruptcy risk. Part (c) corresponds to Assumption 1 in the case of abundant supply of projects. Part (b) also excludes a rather uninteresting case as, similar to the case with an abundant supply of projects, the regulator would simply avoid risk-shifting of the good bank by setting $\bar{n} \leq \hat{n}^{G}(1),{ }^{25}$ which would hardly yield new insights. Thus, Assumption 2 allows us to focus on the most interesting difference of unrestricted and limited supply of projects: if the regulator avoids risk-shifting by the good bank by tight capital equity ratios and mandatory deferral of bonuses, this may backfire by allocating more risky projects to the bank that is inferior in handling those risks.

Given Assumption 2, the optimal regulation can be characterized as follows:

Proposition 4 Suppose that projects are in limited supply and that Assumption 2 holds. Then:

(a) If $S W_{i i i}^{L}\left(\min \left\{\max \left\{\bar{n}_{i i i}^{L}, \hat{n}^{G}(0)\right\}, \hat{n}_{R}^{B}\right\}\right)<S W_{i}^{L}\left(\min \left\{\hat{n}^{G}(1), \hat{n}_{S}^{B}\right\}\right)$, then the unique optimal regulation is $\lambda^{*}=1$ and $\bar{n}^{*}=\min \left\{\hat{n}^{G}(1), \hat{n}_{S}^{B}\right\}$.

(b) If $\bar{n}_{i i i}^{L}>\hat{n}_{R}^{B}$ and $S W_{i}^{L}\left(\min \left\{\hat{n}^{G}(1), \hat{n}_{S}^{B}\right\}\right) \leq S W_{i i i}^{L}\left(\hat{n}_{R}^{B}\right)$, then the optimal regulation is $\bar{n}^{*}=\hat{n}_{R}^{B}$ and any $\lambda$.

(c) If $\hat{n}^{G}(1)>\bar{n}_{i i i}^{L}$ and $S W_{i}^{L}\left(\min \left\{\hat{n}^{G}(1), \hat{n}_{S}^{B}\right\}\right)<S W_{i i i}^{L}\left(\max \left\{\min \left\{\bar{n}_{i i i}^{L}, \hat{n}_{R}^{B}\right\}, \hat{n}^{G}(0)\right\}\right)$, then the optimal regulation is $\bar{n}^{*}=\max \left\{\min \left\{\bar{n}_{i i i}^{L}, \hat{n}_{R}^{B}\right\}, \hat{n}^{G}(0)\right\}$ and $\lambda^{*} \in\{\lambda$ : $\left.\min \left\{\bar{n}_{i i i}^{L}, \hat{n}_{R}^{B}\right\}>\hat{n}^{G}(\lambda)\right\} \cup\{0\}$.

(d) Otherwise, the optimal regulation is $\bar{n}^{*}=\bar{n}_{i i i}^{L}$ and any $\lambda$.

\footnotetext{
25 This would then be the case where $\bar{n}>\hat{n}_{S}^{B}$, i.e. where the bad bank has positive default risk.
} 


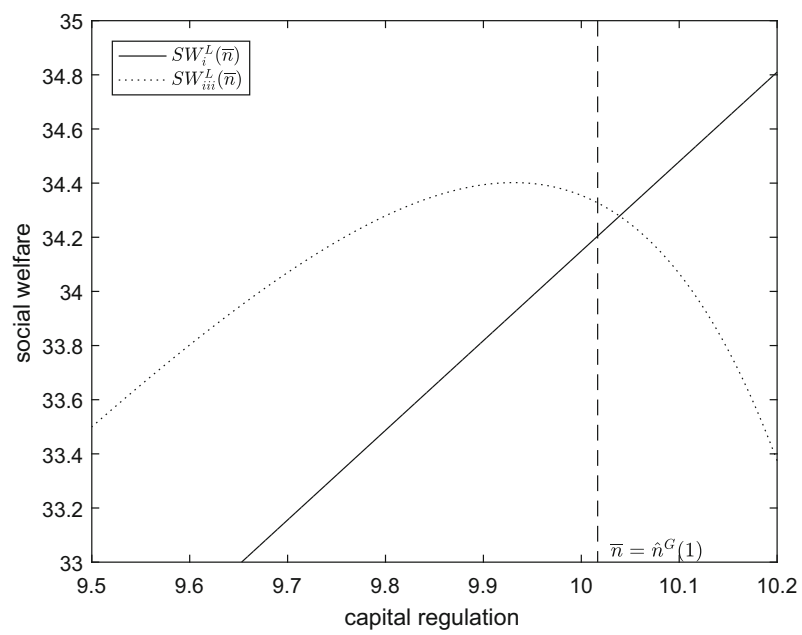

Fig. 3 Limited supply of projects: misallocation of projects in a risk-free banking sector. For $n \leq \hat{n}^{G}(1)$, both banks are free from default risk, and social welfare is given by the solid line. For $n>\hat{n}^{G}(1)$, the good bank prefers risky projects, and social welfare is given by the dotted concave curve. The optimal capital regulation at $\lambda=1$ is slightly above $\hat{n}^{G}(1)$, as risk-shifting by the good bank improves the pool from which the bad bank's projects are drawn. Reducing mandatory deferral of compensation $\lambda$ shifts the threshold $\hat{n}^{G}(\lambda)$ (vertical dashed line) to the left, which is social welfare enhancing as risk-shifting incentives for the good bank are maintained while putting fewer projects at risk of default

Parts (a), (b) and (d) correspond to the respective cases discussed in Proposition 2, but taking into account that the optimal regulation conditional on avoiding any default risk is now $\min \left\{\hat{n}^{G}(1), \hat{n}_{S}^{B}\right\}$ instead of $\hat{n}^{G}(1)$. The main difference introduced by the limited supply of projects is discussed in Part (c), which is illustrated in Fig. 3 for the case where $\hat{n}^{G}(1)<\hat{n}_{S}^{B}$. The vertical, dashed line represents $\bar{n}=\hat{n}^{G}(1)$, whereas the solid and the dotted curves represent $S W_{i}(\bar{n})$ and $S W_{i i i}(\bar{n})$, respectively. Suppose the regulator wants to re-allocate safe projects from the good to the bad bank, because the bad bank is inferior in managing risky projects. To induce risk-shifting by the good bank, the regulator could set $\bar{n}>\hat{n}^{G}(1)$, which still keeps the bad bank risk-free due to $\hat{n}^{G}(1)<\hat{n}_{R}^{B}$, and which is more efficient since, for some capital regulations slightly to the right of the vertical dashed line representing $\hat{n}^{G}(1), S W_{i}(\bar{n})<S W_{i i i}(\bar{n})$. Thus, the higher return of risky projects in the good compared to the bad bank overcompensates the expected social costs of the good bank's potential bankruptcy. However, it can be superior to let the good bank incur default risk, but with less projects at stake due to $\bar{n}_{i i i}^{L}<\hat{n}^{G}(1)$. The only way of making the good bank fund less projects while still retaining its risk-taking incentives is to reduce $\lambda$, which would move the vertical dashed line to the left. In the example displayed in Fig. 3, the optimal fraction of mandatory deferral of compensation is such that the vertical dashed line intersects the dotted curve $S W_{i i i}(\cdot)$ at the latter's peak. If even $\bar{n}_{i i i}^{L}<\hat{n}^{G}(0) \leq \hat{n}_{S}^{B}$, then the uniquely optimal regulation will even require $\lambda=0$.

This case thus illustrates why a limited supply of projects in a heterogenous banking sector may provide a rationale for early compensation, even from a social welfare perspective: Mandatory deferral of compensation reduces the risk-taking incentives of 


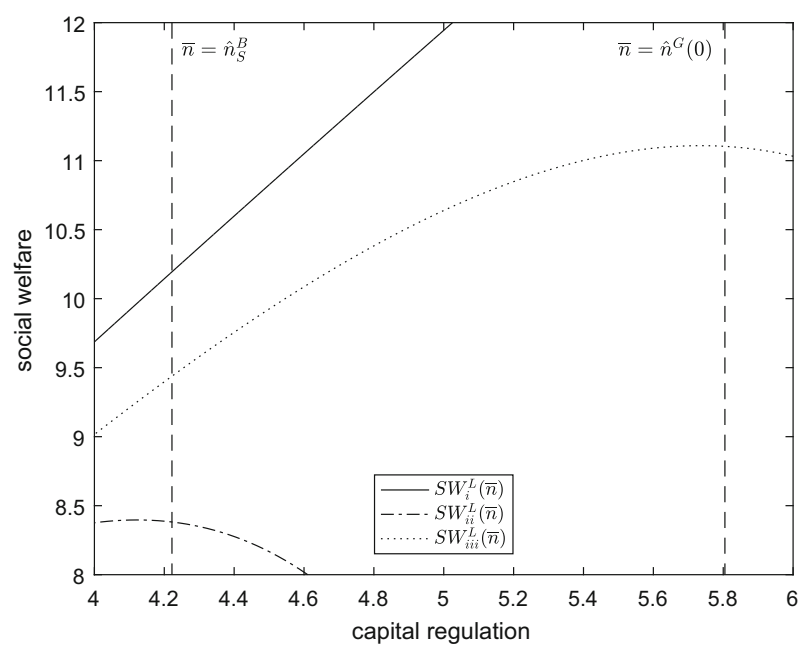

Fig. 4 Limited supply of safe projects: misallocation of projects with default risk. For $n \leq \hat{n}_{S}^{B}$, both banks are free from default risk, and social welfare is given by the solid line. For $\hat{n}_{S}^{B}<n \leq \hat{n}^{G}(0)$, the bad bank has positive defualt risk after the good bank has selected their all-safe portfolio. For $n>\hat{n}^{G}(0)$, the good bank prefers risky projects, which removes the bad bank's default risk, and social welfare is given by the dotted concave curve. Hence, the optimal capital regulation at $\lambda=0$ is slightly above $\hat{n}_{G}(0)$. Increasing mandatory deferral of compensation $\lambda$ would shift the threshold $\hat{n}_{G}(\lambda)$ (right vertical dashed line) to the left, which is social welfare reducing as more projects would be at risk of default

the good bank, which might prefer safe projects if and only if the part of compensation that needs to be deferred is sufficiently large. As a consequence, more risky projects are misallocated to the bad bank. Thus, allowing for early compensation may enable the bad bank to fund more safe projects without jeopardizing too many risky projects in the good bank.

Next, consider the case displayed in Fig. 4 , in which $\hat{n}_{S}^{B}$, represented by the left vertical dashed line, is smaller than $\hat{n}^{G}(0)$, represented by the right vertical dashed line. This means that, for the maximum number of projects that avoids risk shifting by the good bank even with early compensation only $(\lambda=0)$, the bad bank would face positive default risk. A tight capital regulation may then reduce welfare as too few safe projects are left over in the pool the bad bank draws its projects from. Again, the regulator may wish to trigger risk-shifting by the good bank by allowing for early compensation: The area between the vertical dashed lines in Fig. 4 displays the set $\left(\hat{n}_{S}^{B}, \hat{n}^{G}(0)\right]$ of capital requirements that induce case (ii) of Proposition 3 absent any requirement to defer compensation $(\lambda=0)$. Due to our Assumption 2, the regulator wants to avoid this case, which is illustrated in our example by the low position of the dash-dot curve $S W_{i i}(\cdot)$. The optimal capital requirement outside this area is $\hat{n}^{G}(0)$, in which case the banking sector would be quite large, with the good bank being at risk of default. Introducing mandatory deferral of compensation will then move the right vertical dashed line even further right, which reduces social welfare for the capital requirement $\bar{n}=\hat{n}^{G}(\lambda)$. At the same time, the optimal default-risk free regulation $\bar{n}=\hat{n}_{S}^{B}$ may still be less attractive. Hence, $\lambda=0$ is the strictly optimal regulation in this case. 
Both examples just discussed have in common that social welfare under the optimal regulation when the banking sector is free from default risk (case (i) of Proposition 3) is below the maximum social welfare when only the good bank has positive default risk (case (iii) of Proposition 3). Recall that this can never occur under abundant supply of projects. In the example discussed in Fig. 3, $S W_{i}(\bar{n})<S W_{i i i}(\bar{n})$ for any capital regulation $\bar{n}$. The difference between cases (i) and (iii) of Proposition 3 is that the good bank funds an all-safe portfolio in case (i) and an all-risky portfolio in case (iii). If supply of projects was abundant, the bad bank's portfolio would be identical in both cases, so that, for given portfolio sizes, social welfare in case (i) strictly dominates. However, if supply of projects is limited, the pool of projects from which the bad bank draws randomly contains more safe projects if the bad bank funds an all-risky portfolio, thus introducing a countervailing effect. The fewer projects there are over all, the more pronounced will this effect be, and the more likely will the countervailing effect be to dominate.

In the example discussed in Fig. 4, the safe projects that the good bank funds under capital regulations slightly below $\hat{n}_{G}(\lambda)$ make the project pool available for the bad bank so risky that it is at risk of default, whereas it is risk free for capital regulations slightly above $\hat{n}_{G}(\lambda)$ in which case the good bank funds an all-risky portfolio. In other words, increasing the number of projects that both banks are allowed to fund removes the bad bank's default risk. By contrast, if the supply of projects was abundant, so that the bad bank's portfolio was independent of the good bank's project choice, both banks are always weakly more likely to default as the capital regulation is being relaxed. ${ }^{26}$

In summary, we have shown that the optimal mix of regulations for bank capital and manager compensation may change if the supply of projects is sufficiently scarce. ${ }^{27}$ With an abundant supply of projects, mandatory deferral of compensation is weakly dominant: if the regulator wants to keep the good bank risk-free, then the number of projects he can implement via the capital requirement $b$ is strictly increasing in $\lambda$. Otherwise, $\lambda$ is not uniquely defined. With a sufficiently limited number of safe projects, however, it may be better to accommodate risk-shifting by the good bank in order to enable the bad bank, which is inferior in funding risky projects, to fund more safe projects. When avoiding this misallocation, early compensation of managers may be beneficial as it enhances the good bank's incentive for risk-shifting without weakening the capital equity ratio, and hence without increasing the number of projects that are at risk of default.

\footnotetext{
26 Again, introducing bank specific regulation would make each bank's optimal regulation independent of the other bank's threshold for positive default risk. However, in the case of limited supply of projects, both banks' project choices are naturally interwoven via the frequencies of project types in the pool. Hence, our main results that allowing for early compensation in the good bank in order to induce it to take risks and improve the bad bank's project mix while at the same time keeping the good bank's portfolio, which is at risk of default, small, carries over to this modification of the model.

27 Note that if the supply of projects is limited but still large, optimal regulation qualitatively corresponds to the case where projects are in abundant supply. In other words, all results of the model converge to the limit case of an abundant supply of projects as the number of projects in the economy gets large.
} 


\section{Discussion}

In this section, we discuss the robustness of our results with respect to modifications of our main assumptions.

Decoupling the ability to screen projects with ability to manage risky projects. In our main model, we have assumed that the good bank is not only superior in managing risky projects but is also the bank that can distinguish between safe and risky projects. In an extended version (available on request), we have also considered the case where it may be either the good or the bad bank that can screen projects, and where the regulator can only assign probabilities to these two cases. To summarize the main additional insights, consider first the case where it is sure certain that only the bad bank can screen projects and assume that projects are in abundant supply. Then, just as in the main model, full mandatory deferral of compensation $(\lambda=1)$ is optimal as this maximizes the size of the banking sector that can be implemented without riskshifting. Interestingly, this maximum size is now larger as, due to its lower capability of managing risky projects, the bad bank's risk-shifting incentive is smaller than the good bank's. Thus, with an abundant supply of safe projects, social welfare is larger when only the bank that is worse in managing risky projects can screen project types.

The main difference to the main model, however, arises in case of a limited supply of safe projects: In our main model, mandatory deferral of compensation can backfire as avoiding risk-shifting by the good bank increases the fraction of risky projects in the bad bank's portfolio. Thus, $\lambda<1$ could be optimal to accommodate risk-shifting by the good bank and to avoid a misallocation of project types between the two banks. This cannot happen if only the bad bank can screen projects as $\lambda<1$ would increase the risk-shifting incentives by the bad bank which is always socially detrimental. Thus, the case where only the bad bank can screen projects reinforces the benefits of mandatory deferral of compensation. Note that, by contrast to the case of abundant supply of projects, social welfare tends to be lower when the bad bank can screen project types.

In case of uncertainty, the optimal regulation depends on the probability $\xi$ that it is the good bank which can screen project types. With an abundant supply of projects, the regulator will always set $\lambda=1$ and can certainly avoid risk-shifting when restricting the number of projects such that even the good bank prefers safe projects. If $\xi$ is high, then this regulation tends to be superior. If $\xi$ is low, then the regulator may take the risk of allowing for more projects, which avoids risk-shifting if and only if it is the bad bank that can screen project types. Analogously, in case of limited supply of safe projects, the regulator tends to set $\lambda<1$ if $\xi$ is high and $\lambda=1$ if $\xi$ is low. While our extension restricts attention to the case where it is uncertain which of the two bank types can screen projects, a similar trade-off would arise when assuming instead that a fraction $g$ of good banks and a fraction $b$ of bad banks can screen projects. The higher $g$ and the lower $b$, the higher is ceteris paribus the regulator's incentive to avoid risk-shifting also for the good bank with an abundant supply of projects, and to set $\lambda<1$ to accommodate risk-shifting only for the good bank in case of limited supply. 
Restriction of banking regulation to $\lambda$ and $b$ To restrict attention to the external agency problem in a simple way, we have assumed that shareholders can observe the managers' project choices, which is the most convenient assumption to ensure that they can implement their preferred projects. In order to legally enforce the compensation mechanism, however, the project choice does not only need to be observable, but also verifiable. From a theoretical point of view, verifiability would then also allow a project choice-dependent regulation; something which is not considered in our analysis.

In order to account for this potential objection against our approach, we have also analyzed an extended version of our model with the following information structure: In this extended version, there are two project types, $B$ and $A$. Project type $B$ is always risky, and thus identical to the risky project $R$ in our main model. For project type $A$, however, it is ex ante uncertain whether it is of type $S$ (which happens with probability $p$ ) or $R$ (with the counter-probability $1-p$ ). Analogously to the main model, we assume that the manager of the good bank can observe whether a project is of type $A$ or type $B$, while the manager of the bad bank, shareholders and regulators cannot.

Next, we assume that the choice of project types $A$ and $B$ is private information to the good bank's manager, i.e. it is neither observable nor verifiable which project type has been chosen. The actual portfolio, however, which consists of risky projects $R$ and safe projects $S$, is observable and verifiable. And as the observation of the actual portfolio provides a stochastic signal on the project choice, the shareholder can still implement his preferred project choice with respect to $A$ and $B$ by making the compensation contingent on the percentage of project types $S$ and $R$ in the actual portfolio. Specifically, if the shareholder wants the manager to fund $n_{A}^{G}$ and $n_{B}^{G}$ projects, the compensation will only be paid if $n_{S}^{G}=n_{A}^{G}$ and $n_{R}^{G}=n_{B}^{G}$.

The theoretical advantage of this extended model is that the information structure now implies that regulators cannot punish shareholders (or managers) if the portfolio is too risky from a social point of view: Since even projects of type $A$ can turn out to be risky, the regulator cannot perfectly infer from the actual portfolio or from the return structure which project type the good bank has chosen. And as fines imposed by regulators will generally be upheld in court only if the regulator can provide enough evidence that there was negligence or bad intention, stochastic signals can be seen as insufficient. This setting hence endogenizes why the mechanism sets for shareholders and regulators are different. ${ }^{28}$ This theoretical benefit, however, comes at the expense of a far more involved model without changing our results qualitatively, so that we relegated the extended model to an "Appendix" that is available on request.

Other costs of deferred compensation. In our paper, the higher costs of deferred compensation for shareholders take the form of a re-distribution - deferred compensation reduces the part of the manager's salary shareholders can externalize in case of default. Other papers assume that deferred compensation comes at a real preference cost as bank managers are risk-averse or have higher discount rates than the institutions they

\footnotetext{
28 Note that, for the bad bank, different capital equity ratios would be meaningless anyway as this bank itself cannot distinguish between project types A and B.
} 
work for (see e.g. Ray 2002,Grenadier and Wang 2005, Sect. 5, Inderst and Pfeil 2013, and Thanassoulis 2012). ${ }^{29}$

Adding those costs to our model would reinforce the benefits of early compensation from the shareholder's perspective, since deferred compensation is uncertain and paid out later. With risk aversion and positive default risk, the manager would demand even more in the early stage whenever part of the compensation is deferred. The managers' risk aversion would thus reduce the shareholders' incentives to implement the risky project as the managers' participation constraint would require a higher expected salary. As a consequence, discouraging risk-shifting in case of deferred compensation requires less restrictive capital requirements. This implies that, without a potential misallocation of risky projects, risk aversion is good news as it allows for a larger banking sector without inducing risk-shifting. At the same time, the potential misallocation of risky projects would arise already at lower levels of $\lambda$. Risk aversion would hence influence the fine tuning of the two regulatory instruments, but the trade-offs identified in our paper would still arise.

Note, however, that neither risk aversion nor the manager's discount rate would affect the shareholder's ranking of safe and risky projects without default risk as the manager could then be sure to receive the whole compensation anyway. Without default risk, a higher discount rate for the manager increases the advantage of early compared to late compensation, but not the ranking between safe and risky projects. Thus, a positive default risk is both a sufficient and necessary condition to make our point. The drawbacks of deferred compensation usually discussed in the literature could not substitute for the risk of default.

More general assumptions on project returns. Two of our assumptions on project returns and the heterogeneity of banks which drive our results are highly stylized, so that they deserve a brief discussion.

First, to capture systematic risk, we have assumed that risky projects are perfectly correlated, so that either all of them are successful or all of them fail. Instead, we could have assumed that a portfolio of measure $n$ of correlated projects yields $\operatorname{tn} X$, where $t \in[0,1]$ is a random variable. Then, $t$ would indicate the realization of the systematic risk in the loan portfolio. In addition, we could assume that safe projects also bear some risk. All we need is that there are different kinds of projects leading to different probabilities of bank failure, and that shareholders may prefer the socially inferior more risky project type.

Second, our set-up implies that the bad bank has no advantage over the good bank, and would thus be kicked out of the market in case of competition for equity. However, besides the fact that good banks may simply be in short supply, all we actually need is that the good bank has a comparative advantage for managing risky projects, i.e. our results would also appear in a model where the bad bank is better at managing safe projects. Note that, in the latter case, a misallocation of too many risky projects to

\footnotetext{
29 Note that the standard derivation of the CAPM also assumes that shareholders risk-averse, i.e. it cannot be taken for granted that managers are more risk-averse than shareholders. This suggests that contracts between shareholders and managers somehow account for attitudes towards risk, which mitigates the issue of an internal agency problem in case of risk-aversion his scenario.
} 
the bad bank could still be the equilibrium outcome, because only the good bank can distinguish between project types. Thus, the good bank may have an incentive to fund all-safe portfolios whenever these projects have higher absolute return, even when the bad bank is superior in managing those projects.

\section{Conclusion}

We analyze the interplay of capital requirements and mandatory deferral of bankers' compensation in a model where two heterogenous banks can fund safe and risky projects. While managers in the good bank can distinguish between safe and risky projects, they can't in the bad bank. As a second advantage of good banks, we assume that they get higher expected return from risky projects than bad banks. By designing the compensation schemes for managers, shareholders ultimately decide about the good bank's portfolio composition. Regulators have two instruments for reducing the shareholders' incentives for risk-shifting, capital requirements which determine the number of projects that can be funded, and a percentage of mandatory deferral of compensation.

We first confirm three theoretical insights that have partially already been derived in other frameworks: First, shareholders strictly prefer early compensation to deferred compensation if there is positive default risk, which allows to externalize part of the manager's expected compensation from shareholders to creditors. Second, banks protected by limited liability prefer either an all-risky or an all-safe portfolio to a mixed portfolio as, for given expected return, the benefit of risky projects is increasing in the default risk. And third, all-risky portfolios are funded if and only if capital equity ratios and the levels of mandatory deferral of compensation are sufficiently low.

Based on these insights, we focus on the interplay between capital equity ratios and mandatory deferral of compensation. When both project types are in an abundant supply, then there is no interdependency of the two banks' portfolios. For this situation, we find that mandatory deferral of compensation has no downside: The higher the percentage of deferred compensation, the lower is the shareholders' risk appetite, and the larger hence the number of projects a regulator can allow via capital requirements without inducing risk-shifting. With respect to the shareholders' risk appetite, capital equity ratios and mandatory deferral of compensation are substitutes, but deferred compensation is superior as it increases the socially optimal size of the financial sector. Our approach neglects potential costs of deferred compensation such as higher discount rates of managers or risk aversion, but the result that a higher percentage of deferred compensation allows for a larger banking sector without triggering riskshifting seems interesting.

A potential drawback of mandatory deferral of compensation arises in the second situation where we assume that both project types are in limited supply. As a consequence, the good bank's preference for either safe or risky projects influences the bad bank's portfolio composition. Since good banks are better at managing risky projects, the optimal regulation may then be to accommodate risk-shifting in the good bank, thereby leaving more safe projects to the bad bank. Then, mandatory deferral of compensation is no longer necessarily superior to tight capital equity ratios. Incentives for 
risk-shifting in the good bank can be triggered by either a low capital equity ratio (and hence a high number of projects the bank is allowed to fund for given equity) or a high fraction of early compensation. And when the regulator wants to avoid that too many projects are funded, early compensation is superior.

Our point that mandatory deferral of compensation may backfire when the bad bank's project portfolio depends on the good bank's project choice is likely to be even more important when one allows for free entry of banks. With free entry of banks, unfunded profitable projects would not exist in equilibrium, so that the case of limited project supply is the relevant one. Thus, entry would compound the scarcity of projects and thereby increase the impact of the good bank's project choice on the bad bank's portfolio. As a reaction, capital regulation might get tighter, which, in turn, establishes an equilibrium market structure by making entry less attractive. ${ }^{30}$

Let us now turn to the regulatory perspective. Concerning the regulation of bankers' pay, our paper makes three points. First, recall from the introduction that in the EU, the bonus cap for bankers can be extended from $100 \%$ of the fixum to $200 \%$ if approved by shareholders. Such a legislation indicates that regulators care mainly about the internal agency problem between shareholders and their managers rather than about the external agency problem between shareholders and third parties. From the perspective of our paper, letting shareholders decide about the timing of compensation would mean that we are entrusting the care of the sheep to the wolf. Second, neglecting other costs as mentioned above and the potential interdependency of portfolios in a heterogenous banking sector, our paper advocates for mandatory deferral of compensation. The most interesting result in this respect seems to be that deferred compensation allows for a larger banking sector without triggering risk-shifting. Third, however, our findings for the case with a limited supply of projects calls for a more careful analysis of the respective situation, because the relative benefits and costs of strict capital equity ratios and mandatory deferral of compensation then depend on the model's parameters.

The impact of the (sophisticated) good bank's risk appetite on the (less sophisticated) bad bank's portfolio in Sect. 4 relates our paper to the discussion of regulations tailored specifically for systemically relevant financial institutions. One of the motivating observations for our analysis is that the financial crisis was not exclusively triggered by (large) private banks whose shareholders may benefit from risk-shifting. In Germany, for instance, federal state banks ("Landesbanken"), which are obliged to account for public interest, also mis-invested large amounts into risky assets, and then needed to be bailed out with tax payers' money. It is often argued that those banks are less experienced in identifying and managing risky projects, but that they might also have incentives for excessive risk-taking due to the prospect of public bail-outs. (see e.g. Schmielewski and Wein 2012). Then, reducing the number of safe projects may lead to a misallocation of risky projects to less capable banks.

\footnotetext{
30 The exact characterization of equilibrium in this extended model depends on which type of bank would be more likely to enter. While good banks are more profitable and, therefore, have higher incentives to enter, it is plausible to assume that the talent required by good banks is scarce in an economy, which makes the marginal bank more likely to be the bad type.
} 
Thus, while our findings for an abundant supply of both project types call unambiguously for strict regulations, the setting where the portfolios of less sophisticated banks depend on the project choice of more sophisticated institutions leads to an additional perspective on the current tendency to impose stricter regulations on large, globally operating banks while, at the same time, "minimizing the burden on smaller, less complex financial institutions" (Board of Governors of the Federal Reserve System, July 2013, p.1). In the US, for instance, only the eight largest banks are subject to Basel III regulations, so that these banks face tighter capital equity ratios than smaller banks do. ${ }^{31}$ Of course, we are aware of the fact that the systemic risk of bank failure is increasing in the size of the respective financial institutions, but when systemically important banks are also superior at managing risks, this may come at the expense of transferring risky projects to less qualified banks or even to financial institutions in the shadow banking sector which are likely to be less cautious in managing risky projects. Recent developments show that this shift towards shadow banking needs to be taken seriously as, according to a release of the Board of Governors of the Federal Reserve System from July 2, 2013, the global shadow banking system has increased from about 28000 billion US\$ in 2002 to about 70000 billion US\$ in 2011 (see Górnicka (2016) for a recent theoretical analysis of the interplay of regular banks and shadow banks). The original tendency in the Basel process with the Internal Ratings Based Approach was pretty much in favor of large sophisticated banks, and regulations on systemically important banks balancing this tendency were clearly required. Our model provides arguments not to overshoot in the opposite direction.

An important discussion on banking regulation refers to the potential procyclicality of capital requirements. As equity decreases in downturns, the number of projects banks are allowed to fund decrease whenever the capital equity ratio ( $b$ in our model) is kept constant, which may reinforce macroeconomic risks caused by cyclical fluctuations. In addition to lower equity, the number of safe projects in the economy is also likely to decrease during downturns. Hence, the number of projects allowed via capital equity ratio needs to be low for two reasons, due to lower equity and because the bad bank's project pool consists mainly of risky projects. If, however, the maximum size of the banking sector that avoids bankruptcy risk is too small during downturns and the regulator wants to avoid a credit crunch, he might wish to encourage risk-shifting by the good bank. In addition to countercyclical capital buffers, our model suggests that this could be done by allowing part of the compensation to be early $(\lambda<1)$. Similar considerations suggest that the optimal regulatory policy may vary across countries if the number (or percentage) of safe projects is country-specific. While beyond the scope of this paper, our findings on the impact of the availability of safe compared to risky projects on the interplay of mandatory deferral of compensation and capital equity ratios might also be useful for developing insights into country-specific banking regulation.

\footnotetext{
31 A potentially important countervailing effect arises from the fact that systemically important banks are more likely to qualify for internal rating according to the IRB-approach, which saves them capital. The essence of the of the IRB-approach was retained in the revised Basel III-capital regulation; see Basel Committee on Banking Supervision (2015) and European Banking Authority (EBA) (2015).
} 
Open Access This article is distributed under the terms of the Creative Commons Attribution 4.0 International License (http://creativecommons.org/licenses/by/4.0/), which permits unrestricted use, distribution, and reproduction in any medium, provided you give appropriate credit to the original author(s) and the source, provide a link to the Creative Commons license, and indicate if changes were made.

\section{Appendix}

\section{A Proof of Lemma 1}

Each bank $i$ simultaneously chooses the project portfolio $n_{S}^{i}, n_{R}^{i}$, the manager's contractual compensation $C_{i}$ and the share $\alpha_{i} \geq \lambda$ of that compensation to be deferred so as to maximize its ex-ante expected value. Define $Z_{i}:=E+(k X-1) n_{S}^{i}-n_{R}^{i}$ as bank $i$ 's value in the case where the risky projects fail and in absence of any compensation for the manager. There are the following cases: ${ }^{32}$

Case (a): If $Z_{i} \geq C_{i}$, the bank can pay $C_{i}$ to the manager in full even if the risky projects fail. Hence, the manager's participation constraint is satisfied if $C_{i}=e$, and the bank's expected value is given by (1).

Case (b): If $\left(1-\alpha_{i}\right) C_{i} \leq Z_{i}<C_{i}$, the firm's value upon failure of the risky projects is positive but insufficient to pay the deferred fraction $\alpha_{i} C_{i}$ of the manager's contractual compensation. Hence, the manager's participation constraint is binding if $\left(1-\alpha_{i}\right) C_{i}+\theta^{i} \alpha_{i} C_{i}+\left(1-\theta^{i}\right)\left[Z_{i}-\left(1-\alpha_{i}\right) C_{i}\right]=e$, which is equivalent to $C_{i}=\frac{e-\left(1-\theta^{i}\right) Z}{\theta^{i}}$. Again, the bank's resulting expected value is given by (1).

Case (c): If $Z_{i}<\left(1-\alpha_{i}\right) C_{i}$, then failure of the risky projects wipes out the bank's entire cash, which means that the deferred fraction of the manager's compensation is paid out only if the risky projects succeed. Hence, the manager's participation constraint is binding if $\left(1-\alpha_{i}\right) C_{i}+\theta^{i} \alpha_{i} C_{i}=e$, which is equivalent to $C_{i}=\frac{e}{1-\left(1-\theta^{i}\right) \alpha_{i}}$.

The bank's value is positive only if the risky projects succeed, in which case the full contractual compensation $C_{i}$ is paid out to the manager. Hence, the bank's expected value is

$$
\begin{aligned}
\pi_{i}\left(\alpha_{i}\right) & =\theta^{i}\left[E+(k X-1) n_{S}^{i}+(X-1) n_{R}^{i}-C_{i}\right] \\
& =\theta^{i}\left[E+(k X-1) n_{S}^{i}+(X-1) n_{R}^{i}\right]-\frac{\theta^{i} e}{1-\left(1-\theta^{i}\right) \alpha_{i}},
\end{aligned}
$$

which is strictly decreasing in $\alpha_{i}$.

Summary: The bank's expected value in case (c) is larger than in cases (a) and (b), which is given by (1), if and only if $\alpha_{i}<\frac{e-Z_{i}}{e-\left(1-\theta^{i}\right) Z_{i}}$. Hence, we can summarize the

\footnotetext{
32 Note that we can, without any further loss of generality, restrict attention to the case where $C_{i} \leq$ $E+(k X-1) n_{S}^{i}-(X-1) n_{R}^{i}$, i.e., where succeeding risky projects allow the bank to compensate the manager in full. If $C_{i}$ was above that threshold, the manager's expected compensation would be equal to the ex-ante expected bank value in Case (b) below, and even above that in Case (c). This is in line with a binding participation constraint only if $e$ is at least as large as the ex-ante expected bank value, which we have already excluded by assuming $e<E$. Furthermore, this latter assumption also implies that there are always enough funds available to pay the early part $\left(1-\alpha_{i}\right) C_{i}$ of the compensation.
} 
three cases concluding that the bank chooses $\alpha_{i}$ so as to maximize expected value

$\pi_{i}\left(\alpha_{i}\right)= \begin{cases}\theta^{i}\left[E+(k X-1) n_{S}^{i}+(X-1) n_{R}^{i}\right]-\frac{\theta^{i} e}{1-\left(1-\theta_{i}\right) \alpha_{i}}, & \text { if } \alpha_{i}<\frac{e-Z_{i}}{e-\left(1-\theta^{i}\right) Z_{i}} \\ E+(k X-1) n_{S}^{i}+\left(\theta^{i} X-1\right) n_{R}^{i}-e, & \text { otherwise. }\end{cases}$

subject to $\alpha_{i} \geq \lambda$. Noting that $\pi_{i}\left(\alpha_{i}\right)$ is continuous, it follows that $\alpha_{i}=\lambda$ is the unique optimum if $\lambda<\frac{e-Z_{i}}{e-\left(1-\theta^{i}\right) Z_{i}}$, which is equivalent to the condition $E+(k X-1) n_{S}^{i}-$ $n_{R}^{i}<\frac{1-\lambda}{1-\left(1-\theta^{i}\right) \lambda} e$ for part (i) of the Lemma, and that the bank's expected value is independent of $\alpha_{i}$ otherwise.

\section{B Proof of Proposition 1}

$\underline{P a r t}(a)$ : Bank $G$ 's expected value when carrying out project plan $\left(n_{S}^{G}, n_{R}^{G}\right)$ is

$$
\begin{aligned}
& \pi_{G}\left(n_{S}^{G}, n_{R}^{G}\right) \\
& = \begin{cases}\theta^{G}\left[E+(k X-1) n_{S}^{G}+(X-1) n_{R}^{G}\right]-\frac{\theta^{G} e}{1-\left(1-\theta^{G}\right) \lambda}, & \text { if } E+(k X-1) n_{S}^{G}-n_{R}^{G} \\
E+(k X-1) n_{S}^{G}+\left(\theta^{G} X-1\right) n_{R}^{G}-e, & <\frac{1-\lambda}{1-\left(1-\theta^{G}\right) \lambda} e\end{cases}
\end{aligned}
$$

which is continuous, and increasing in $n_{S}^{G}$ and $n_{R}^{G}$ within both cases. Hence, $n_{S}^{G}+n_{R}^{G}=$ $\bar{n}$ in optimum. Substituting for $n_{R}^{G}=\bar{n}-n_{S}^{G}$ yields

$$
\begin{aligned}
& \pi_{G}\left(n_{S}^{G}\right) \\
& \quad= \begin{cases}\theta^{G}\left[E+(X-1) \bar{n}-(1-k) X n_{S}^{G}\right]-\frac{\theta^{G} e}{1-\left(1-\theta^{G}\right) \lambda}, & \text { if } E-\bar{n}+k X n_{S}^{G}<\frac{1-\lambda}{1-\left(1-\theta^{G}\right) \lambda} e ; \\
E+\left(\theta^{G} X-1\right) \bar{n}+\left(k-\theta^{G}\right) X n_{S}^{G}-e, & \text { otherwise, }\end{cases}
\end{aligned}
$$

Clearly, $\pi_{G}$ (.) is decreasing in $n_{S}^{G}$ in the upper case, which is relevant for low $n_{S}^{G}$, and increasing in the lower case (high $n_{S}^{G}$ ). Hence, the optimal choice of $n_{S}^{G}$ is either zero or $\bar{n}$. Substituting for these boundary solutions yields the result that $\pi_{G}(0) \leq \pi_{G}(\bar{n})$ if and only if $\bar{n} \leq \frac{E-\frac{1-\lambda}{1-\left(1-\theta^{G}\right) \lambda} e}{1-\frac{k-\theta^{G}}{1-\theta^{G}} X}$.

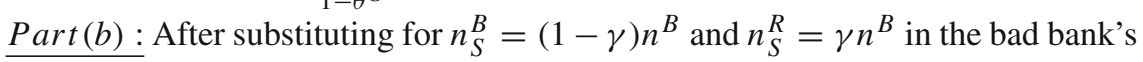
profit given by (1) and (2), the resulting profit is continuous and increasing in $n^{B}$. Furthermore, there is a positive default risk if and only if $Z_{B}<e$, which is equivalent to $n>\hat{n}^{B}$.

$\operatorname{Part}(c): \hat{n}^{G}(\lambda)$ is constant in $\gamma$, and $\hat{n}^{B}$ is strictly decreasing in $\gamma$. If $\gamma=0$, then $\hat{n}^{B} \overline{<0<\hat{n}^{G}}(\lambda)$ for every $\lambda$. If $\gamma=1$, then $\hat{n}^{B}>E-e>\hat{n}^{G}(\lambda)$ for every $\lambda$. Hence, for every $\lambda$, there must be some $\hat{\gamma}(\lambda) \in(0,1)$ such that $\hat{n}^{G}(\lambda)<\hat{n}^{B}$ if and only if $\gamma<\hat{\gamma}(\lambda)$. 


\section{Proof of Proposition 3}

Allocations and default probabilities are immediately implied by Proposition 1:

Existence of $\hat{n}_{S}^{B}$ follows from the fact that the left-hand side of (5) is increasing and the right-hand side decreasing in $\hat{n}_{S}^{B}$. However, $\hat{n}_{R}^{B}$ may not exist: Note first that $0<\frac{E-e}{1-\left(1-\gamma_{R}(0)\right) k X}$. Hence, $\hat{n}_{R}^{B}$ is well defined if there exists some $n>0$ for which $n>\frac{E-e}{1-\left(1-\gamma_{R}(n)\right) k X}$, which is, using $1-\gamma_{R}(n)=\frac{N_{S}}{N_{R}+N_{S}-n}$, equivalent to

$$
\left(N_{R}+N_{S}-n-N_{S} k X\right) n-(E-e)\left(N_{R}+N_{S}-n\right)>0,
$$

and, thus,

$$
\left(N_{R}+N_{S}-n\right)(n-(E-e))-n N_{S} k X>0 .
$$

The left-hand side of (8) has a unique maximum at $n=\frac{1}{2}\left(N_{R}+N_{S}+E-e-N_{S} k X\right)$, at which, after rearranging, the left-hand side takes the value $-(E-e) N_{S} k X+\frac{1}{4}\left(N_{R}+\right.$ $\left.N_{S}-(E-e)-N_{S} k X\right)^{2}$, which may not always be positive.

$\hat{n}_{S}^{B}<\hat{n}_{R}^{B}$ can be shown by solving (5) and (6) for $\gamma_{S}\left(\hat{n}_{S}^{B}\right)$ and $\gamma_{R}\left(\hat{n}_{R}^{B}\right)$, respectively, which yields

$$
\begin{aligned}
& \gamma_{S}\left(\hat{n}_{S}^{B}\right)=1-\frac{1}{k X}+\frac{E-e}{\hat{n}_{S}^{B} k X} \\
& \gamma_{R}\left(\hat{n}_{R}^{B}\right)=1-\frac{1}{k X}+\frac{E-e}{\hat{n}_{R}^{B} k X}
\end{aligned}
$$

The right-hand sides of (9) and (10) are the same function, which is decreasing in the threshold capital regulation. Since $\gamma_{S}(\bar{n})>\gamma_{R}(\bar{n})$ for every $\bar{n}$, it follows that $\hat{n}_{S}^{B}<\hat{n}_{R}^{B}$.

\section{Proof of Proposition 4}

Due to Assumption 2, the optimal regulation is either $\min \left\{\hat{n}^{G}(1), \hat{n}_{S}^{B}\right\}$ or

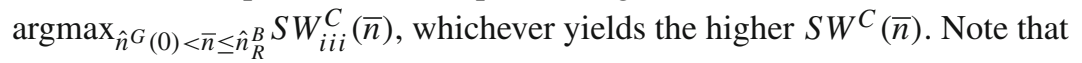

$$
\operatorname{argmax}_{\hat{n}^{G}(0)<\bar{n} \leq \hat{n}_{R}^{B}} S W_{i i i}^{C}(\bar{n}) \subset\left\{\hat{n}^{G}(0), \bar{n}_{i i i}^{O}, \hat{n}_{R}^{B}\right\},
$$

and it is equal to $\hat{n}^{G}(0)$ if $\hat{n}^{G}(0)<\bar{n}_{i i i}^{o}$, and equal to $\hat{n}_{R}^{B}$ if $b_{i i i}^{o}<\hat{n}_{R}^{B}$. Hence, Part (a) follows.

Parts (b)-(d) then deal with the three aforementioned cases in which $\operatorname{argmax} S W^{C}(b)=\operatorname{argmax}_{\hat{n}^{G}(0)<\bar{n} \leq \hat{n}_{R}^{B}} S W_{i i i}^{C}(\bar{n})$ one by one, the conditions for each cases being (i) the condition for the respective maximum of $S W_{i i i}^{C}(\bar{n})$ as just explained, and (ii) the condition that $S W_{i i i}^{C}(\bar{n})$ at this local maximum is larger than the local maximum for $\bar{n} \geq \min \left\{\hat{n}^{G}(1), \hat{n}_{S}^{B}\right\}$. 


\section{References}

Acharya, V. (2009). A theory of systemic risk and design of prudential bank regulation. Journal of Financial Stability, 5(3), 224-255.

Acharya, V., Pagano, M., \& Volpin, P. (2016). Seeking alpha: Excess risk taking and competition for managerial talent. Review of Financial Studies, 29(10), 2565-2599.

Acharya, V., \& Yorulmazer, T. (2007). Too many to fail-An analysis of time-inconsistency in bank closure policies. Journal of Financial Intermediation, 16(1), 1-31.

Admati, A., \& Hellwig, M. (2014). The bankers' new clothes: What's wrong with banking and what to do about it. Princeton: Princeton University Press.

Admati, A. R., \& Pfleiderer, P. C. (2010). Increased-liability equity: A proposal to improve capital regulation of large financial institutions. Discussion paper.

Aghion, P., \& Bolton, P. (1987). Contracts as a barrier to entry. The American Economic Review, 77(3), $388-401$.

Allen, F., Carletti, E., \& Marquez, R. (2011). Credit market competition and capital regulation. Review of Financial Studies, 24(4), 983-1018.

Allen, L. (2004). The basel capital accords and international mortgage markets: A survey of the literature. Financial Markets, Institutions \& Instruments, 13(2), 41-108.

Anginer, D., Demirguc-Kunt, A., Huizinga, H., \& Ma, K. (2016). Corporate governance and bank capitalization strategies. Journal of Financial Intermediation, 26, 1-27.

Bannier, C., Feess, E., \& Packham, N. (2013). Competition, bonuses, and risk-taking in the banking industry. Review of Finance, 17(2), 653-690.

Basel Committee on Banking Supervision. (2015). Ninth progress report on adoption of the Basel regulatory framework.

Bebchuk, L., \& Fried, J. (2010). Paying for long-term performance. University of Pennsylvania Law Review, 158(7), 1915-1959.

Bebchuk, L., \& Spamann, H. (2010). Regulating bankers' pay. Georgetown Law Journal, 98(2), 247-287.

Bell, B., \& Van Reenen, J. (2014). Bankers and their bonuses. Economic Journal, 124(574), F1-F21.

Besley, T., \& Ghatak, M. (2013). Bailouts and the optimal taxation of bonus pay. American Economic Review, 103(3), 163-67.

Bhattacharya, S., Boot, A., \& Thakor, A. (1998). The economics of bank regulation. Journal of Money, Credit and Banking, 30(4), 745-770.

Bijlsma, M. J., Boone, J., \& Zwart, G. (2012). Competition for traders and risk. CEPR discussion paper no. DP8816.

Bolton, P., Freixas, X., \& Shapiro, J. (2012). The credit ratings game. Journal of Finance, 67(1), 85-111.

Bolton, P., Mehran, H., \& Shapiro, J. (2015). Executive compensation and risk taking. Review of Finance, $19(6), 2139-2181$.

Broecker, T. (1990). Credit-worthiness tests and interbank competition. Econometrica, 58(2), 429-452.

Bulow, J., \& Klemperer, P. (2015). Equity recourse notes: Creating counter-cyclical bank capital. Economic Journal, 125(586), F131-F157.

Cheng, I., Hong, H., \& Scheinkman, J. (2015). Yesterday’s heroes: Compensation and creative risk-taking. Journal of Finance, 70(2), 839-879.

Dewatripont, M., \& Tirole, J. (1994). The prudential regulation of banks. Cambridge: MIT Press.

DeYoung, R., Peng, E., \& Yan, M. (2010). Executive compensation and business policy choices at U.S. commercial banks. Federal Bank of Kansas City discussion paper.

Edmans, A., \& Liu, Q. (2011). Inside debt. Review of Finance, 15(1), 75-102.

Eufinger, C., \& Gill, A. (2016). Incentive-based capital requirements. Management Science, 63(12), 41014113.

European Banking Authority (EBA). (2015). Future of the IRB approach. EBA/DP/2015/01.

Fahlenbrach, R., \& Stulz, R. (2011). Bank CEO incentives and the credit crisis. Journal of Financial Economics, 99(1), 11-26.

Feess, E., \& Hege, U. (2012). The basel accord and the value of bank differentiation. Review of Finance, 16(4), 1043-1092.

Gete, P., \& Gomez, J.-P. (2016). Dealing with overleverage: Restricting leverage vs. restricting variable compensation. Discussion paper.

Getter, D. E. (2012). US implementation of the basel capital regulatory framework. Library of Congress: Congressional Research Service. 
Górnicka, L. A. (2016). Banks and shadow banks: Competitors or complements? Journal of Financial Intermediation, 27, 118-131.

Grenadier, S. R., \& Wang, N. (2005). Investment timing, agency, and information. Journal of Financial Economics, 75(3), 493-533.

Hakenes, H., \& Schnabel, I. (2014). Bank bonuses and bailouts. Journal of Money, Credit and Banking, 46(s1), 259-288.

Harris, M., Opp, C. C., \& Opp, M. M. (2017). Bank capital, risk-taking and the composition of credit. Discussion paper.

Hart, O., \& Zingales, L. (2011). A new capital regulation for large financial institutions. American Law and Economics Review, 13(2), 453-490.

Hoffmann, F., Inderst, R., \& Opp, M. M. (2016). Only time will tell: A theory of deferred compensation and its regulation. Discussion paper.

Inderst, R., \& Pfeil, S. (2013). Securitization and compensation in financial institutions. Review of Finance, 17(4), 1323-1364.

Jarque, A., \& Prescott, E. (2010). Optimal bonuses and deferred pay for bank employees: Implications of hidden actions with persistent effects in time. Discussion paper.

Jokivuolle, E., Keppo, J., \& Yuan, X. (2015). Reducing risk-taking by regulating bonuses: EU vs US DoddFrank. http://www.voxeu.org/article/reducing-risk-taking-regulating-bonuses-eu-vs-us-dodd-frank.

Kashyap, A., Rajan, R., \& Stein, J. (2008). Rethinking capital regulation. In Maintaining stability in a changing financial system, Proceedings, Economic Policy Symposium Jackson Hole, Federal Reserve Bank of Kansas City, pp. 431-471.

Kolm, J., Laux, C., \& Lóránth, G. (2016). Bank regulation, CEO compensation, and boards. CEPR discussion paper 11380 .

Miles, D., Yang, J., \& Marcheggiano, G. (2013). Optimal bank capital. Economic Journal, 123(567), 1-37.

Nakamura, L. I. (1993). Loan screening within and outside of customer relationships. Federal Reserve Bank of Philadelphia, working paper no. 93-15.

Pagano, M., \& Jappelli, T. (1993). Information sharing in credit markets. Journal of Finance, 48(5), 16931718.

Phelan, C., \& Clement, D. (2010). Incentive compensation in the banking industry: Insights from economic theory. Federal Reserve Bank of Minneapolis Economic Policy paper 09-01.

Ray, D. (2002). The time structure of self-enforcing agreements. Econometrica, 70(2), 547-582.

Riordan, M. (1993). Competition and bank performance: A theoretical perspective. In C. Mayer \& X. Vives (Eds.), Capital markets and financial intermediation (pp. 328-343). Cambridge: Cambridge University Press.

Schmielewski, F., \& Wein, T. (2012). Are private banks the better banks? An insight into the principal-agent structure and risk-taking behavior of german banks. Journal of Economics and Finance, 39(3), 1-23.

Shaffer, S. (1998). The winner's curse in banking. Journal of Financial Intermediation, 7(4), 359-392.

Squam Lake Group. (2009). Reforming capital requirements for financial institutions. Working paper.

Suntheim, F. (2010) . Managerial compensation in the financial service industry. Discussion paper.

Thanassoulis, J. (2012). The case for intervening in bankers' pay. Journal of Finance, 67(3), 849-895.

Thanassoulis, J. (2014). Bank pay caps, bank risk, and macroprudential regulation. Journal of Banking \& Finance, 48, 139-151.

Wei, C., \& Yermack, D. (2011). Investor reactions to CEOs' inside debt incentives. Review of Financial Studies, 24(11), 3813-3840. 